This item was submitted to Loughborough's Research Repository by the author.

Items in Figshare are protected by copyright, with all rights reserved, unless otherwise indicated.

\title{
Extraction of connected river networks from multi-temporal remote sensing imagery using a path tracking technique
}

\section{PLEASE CITE THE PUBLISHED VERSION}

https://doi.org/10.1016/j.rse.2020.111868

\section{PUBLISHER}

Elsevier BV

VERSION

AM (Accepted Manuscript)

\section{PUBLISHER STATEMENT}

This paper was accepted for publication in the journal Remote Sensing of Environment and the definitive published version is available at https://doi.org/10.1016/j.rse.2020.111868.

LICENCE

CC BY-NC-ND 4.0

\section{REPOSITORY RECORD}

Chen, Huili, Qiuhua Liang, Zhongyao Liang, Yong Liu, and Tingyu Ren. 2020. "Extraction of Connected River Networks from Multi-temporal Remote Sensing Imagery Using a Path Tracking Technique”. Loughborough University. https://hdl.handle.net/2134/12628448.v1. 


\section{Extraction of Connected River Networks from Multi-Temporal Remote Sensing Imagery Using a Path Tracking Technique}

Huili Chen ${ }^{1,2}$, Qiuhua Liang ${ }^{2}$, Zhongyao Liang $^{1}$, Yong Liu ${ }^{1 *}$, Tingyu Ren ${ }^{1}$

1. College of Environmental Science and Engineering, State Environmental Protection Key

Laboratory of All Materials Flux in Rivers, Peking University, Beijing 100871, China.

2. School of Architecture, Building and Civil Engineering, Loughborough University,

Loughborough LE11 3TU, UK

* Corresponding Author:

E-mail: yongliu@pku.edu.cn (Y. Liu); TEL: 861062753184. 


\section{ABSTRACT}

2 Precise delineation of river networks is important for accurate hydrological and flood modelling.

3 Whilst remote sensing (RS) has showed great potential in monitoring hydrological changes

4 over space and time, the existing RS-based methods extract river networks based on local

5 morphologies and seldom take into account the overall hydrological connectivity of the rivers.

6 The existing methods also commonly neglect the effect of seasonal variation of water surfaces

7 and the existence of temporary water bodies, which deteriorate the precision of positioning river

8 networks. To address these challenges, a new two-stage method is developed to Extract

9 spatiotemporal variation of water surfaces based on Multi-temporal remote sensing Imagery and Delineate connected river networks with improved accuracy (EMID method for short) using a path tracking technique. The EMID method delineates connected river networks using (a) multi-temporal imagery and a Random Forest model to synoptically map the location and extent of water surfaces under different hydrological conditions, and (b) an optimization algorithm to find best river paths based on water-occurrence frequency. Four drainage basins with various river morphologies are considered to validate EMID. Comparing with alternative methods, EMID method consistently produces river network results with improved accuracy in terms of stream location, river coverage and network connectivity.

Keywords: Remote Sensing; River Network Delineation; Hydrological Connectivity; Spatiotemporal Variation; Random Forest 


\section{INTRODUCTION}

Precise delineation of river networks is important for flood modelling and risk management (e.g. Ward et al., 2017; Dottori et al., 2018), water resource management (Jones et al., 2008; Poppenga et al., 2010; Gleason \& Smith, 2014), understanding floodplain dynamics (e.g. BoixFayos et al., 2007; Marchese et al., 2017), and characterizing biogeochemical cycles (Cole et al., 2007; Battin et al., 2009; Benstead \& Leigh, 2012; Rosemond et al., 2015). Traditionally, river networks are manually derived from topographic maps, air photos, or satellite imagery (e.g. Bird et al., 2010; Chen et al., 2018; Qin et al., 2018). Manual extraction of river networks is potentially accurate, but also labor intensive and therefore unviable for application over large domains.

A range of methods for automatically delineating river networks from digital elevation models (DEMs) have been developed and reported (e.g. O'Callaghan \& Mark, 1984; Martz \& Garbrecht, 1992; Passalacqua et al., 2010a, 2010b). These DEM-based river network extraction methods are generally developed based on the underlying geomorphological, hydrological and hydraulic processes over the landscapes (Moore et al., 1991). The early DEM-based methods perform well in the steep and high-gradient landscapes where hydrological features such as river banks, peaks and ridgelines are easy to be identified from the available topographic information. However, the applicability of these methods in low-relief landscapes is questionable (Jones et al., 2008; Koenders et al., 2014).

In the last two decades, DEM-based analysis methods have been further developed to extract realistic river networks with much improved accuracy (e.g. Orlandini et al., 2003; Seibert \& McGlynn, 2007; Moretti \& Orlandini, 2008; Orlandini \& Moretti, 2009; Passalacqua et al., 2010a, 2010b; Sofia et al, 2011; Bai et al., 2015a, 2015b; Schneider et al., 2017; Qin et al., 2018; Roelens et al, 2018; Yamazaki et al., 2019). These improved analysis methods usually require and depend on accurate description of land surface topography, i.e., the resolution of adopted DEMs must be able to adequately depict the spatial variability of the terrain under consideration (Orlandini et al., 2012; Orlandini et al., 2014; Moretti \& Orlandini, 2018). Despite their improved performance, these DEM-based methods are not always feasible for practical applications owing to the unavailability of high-resolution $(<10 \mathrm{~m})$ LiDAR DEMs. 
The limited availability of high-resolution DEMs dictates that open-source global DEMs are still widely used and sometimes the only choice in river network extraction, particularly in data-sparse environments. However, the currently used open-source DEMs are confronted with a number of issues including insufficient spatial resolution and significant vertical errors (Chen et al., 2018; Hawker et al., 2018), which are clearly inadequate to support the application of existing DEM-based methods for accurate extraction of river networks (Yang et al., 2015). Another potential limitation of DEM-based methods is their dependence on morphologically defined rivers and elevation attributes, which may not ensure the extracted river channels actually exist. River networks may vary over a short timeframe due to hydrological processes, climatic forcing, along with intensive human activities (Boix-Fayos et al., 2007). These temporal variations of river networks may not be clearly captured by the currently global DEMs.

Satellite imagery, on the other hand, can provide continuous global coverage at high temporal and spatial resolution. Satellite/RS imagery can be used to effectively monitor hydrological changes over space and time. The potential of using RS imagery to recreate river networks has been demonstrated in previous studies (Dillabaugh et al., 2002; Pavelsky \& Smith, 2008; Yamazaki et al., 2014; Yang et al., 2014; Isikdogan et al., 2015; Zeng et al., 2015; Isikdogan et al., 2017; Allen \& Pavelsky, 2018) and several effective RS-based methods have been developed and reported (e.g. Pavelsky \& Smith, 2008; Yang et al., 2014, 2015; Isikdogan et al., 2015, 2017). Most of these existing methods involve the development of a water surface mask to differentiate water and non-water pixels from RS imagery using band or index thresholding, shape-correcting operations, or statistical classification methods. The rasterized water mask is then thinned to create river centerlines of one pixel wide using morphological operations. The morphological methods facilitate the extraction of channelized elements from local morphologies, without considering overall hydrological connectivity (Cazorzi et al., 2013). Neglecting hydrological connectivity may lead to the creation of broken and inconsistent river segments, which may not represent the actual configuration/connectivity of the real-world river networks (e.g. Svoray, 2004; Shen \& Sheng, 2012; Zeng et al., 2015).

Additionally, rivers are one of the most dynamic geomorphological features of landscape (Van et al., 2003). The dynamic behavior of a river system is affected by land use, vegetation, seasonal inundation and soil moisture, and produces the active fluvial processes (Church, 2002; 
Gurnell, 2014; Orengo \& Petrie, 2017). For example, there exists many non-perennial rivers and streams, such as snow-melt streams, rain-fed headwater streams, and spring-fed karstic rivers, which account for more than $50 \%$ of the total length of the global river network (Datry et al., 2014). The dynamic behavior of rivers hinders the use of uniform temporal analysis for hydrological systems (Pekel et al., 2016). These variabilities also pose a great challenge on the existing RS-based methods for river extraction, which commonly extract river networks based on single imagery acquired at one time or over a limited timeframe. Single imagery provides limited information on the hydrological systems that maintain rivers and cannot ensure the extraction of complete river networks.

Furthermore, temporary water surfaces created by seasonal flooding and irrigation cycles (e.g. floodplains, wetlands and paddy fields) (Feng et al, 2012, 2013; Pekel et al., 2016) widely exist and may affect the river extraction results, e.g. by introducing false river channels. Although RS data may potentially capture the temporal change of water surfaces, the impact of water surface variations on river network extraction has not been considered and investigated in previous studies. The existing methods may therefore create different river networks in the same area under different hydrological conditions.

To overcome the shortcomings of the existing RS-based methods, this work develops a new approach to extract connected and complete river networks with improved accuracy. Firstly, it is necessary to map the extent and dynamics of water surface using multi-temporal RS imageries to obtain the information about the water body existence possibility under various flow periods. The water surface extent during high-flow period provides the possibility of detecting and connecting small or intermittent rivers while that during low-flow period is useful for reducing interference of temporary bodies of water and identifying the central part of large rivers. Subsequently, based on the information on the water-occurrence frequency within the domain, an optimization algorithm of identifying best river path is designed to detect the river centerline pixel and delineate a connected network of rivers without any discontinuous or broken river segments. Finally, the new method will be tested and validated in four river basins with low-relief landscapes but different hydrological characteristics and river morphology. 


\section{MATERIALS AND METHODS}

A new methodology framework is proposed to Extract spatiotemporal variation of water surfaces based on Multi-temporal remote sensing Imagery and Delineate connected river networks (EMID hereafter) using a path tracking technique. As illustrated in Fig. 1, EMID involves three key steps, i.e. (1) water surface extraction, (2) river presence possibility calculation, and (3) best river path searching, which will be introduced in detail in the following sub-sections.

Multi-temporal

Imageries acquisition

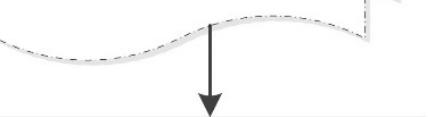

Interference

observations removal

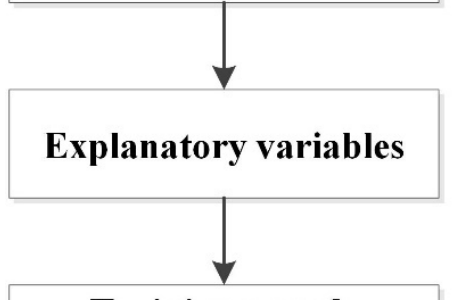

Training sample

selection

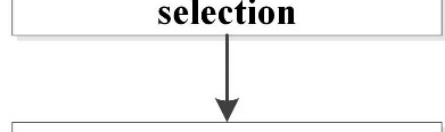

\section{Random Forest model}

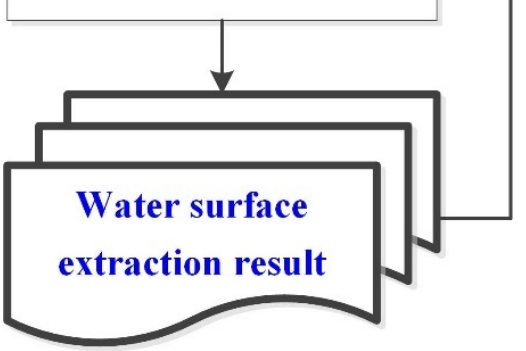

Water-occurrence

frequency

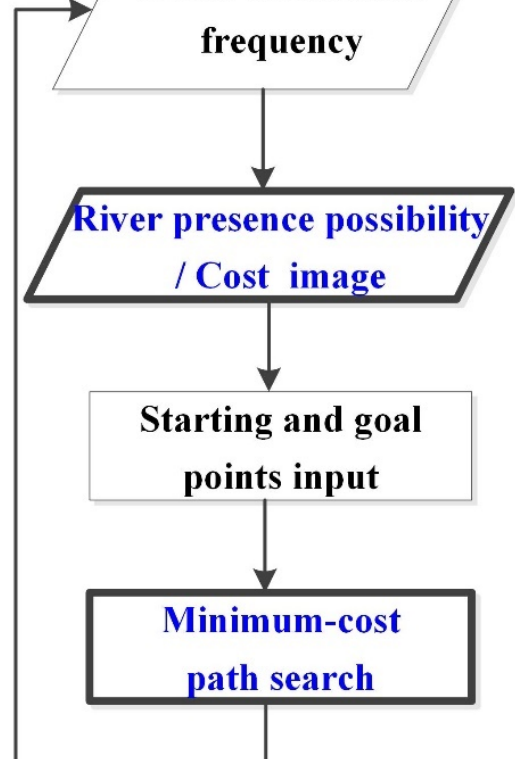

River centerline

pixels detection

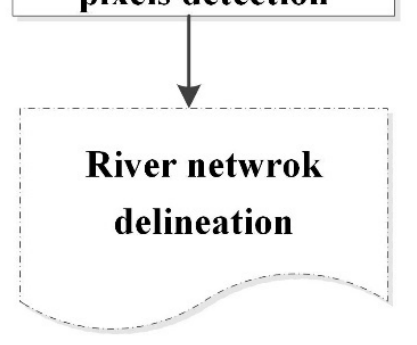

Fig. 1. The EMID framework that combines multi-temporal imagery and a path tracking technique for river network extraction.

\subsection{Water Surface Extraction}


predictor variables is used to map the location and extent of water surfaces under different hydrological conditions.

\section{$121 \quad$ 2.1.1 Acquisition of Satellite Imagery}

122 Landsat imagery is one of the most common types of RS data for mapping water surface, providing multispectral images of global coverage since 1972. Available at a 16-day interval and $30 \mathrm{~m}$ spatial resolution, Landsat imagery can be used to identify the extents and reflect the dynamic changes of water surfaces (e.g. Yamazaki et al., 2015; Tulbure et al., 2016; SchafferSmith et al., 2017). The Landsat 5 Thematic Mapper (TM) imagery between 2000 and 2010 is used in this work to extract the locations and extents of water surfaces under different hydrological conditions. Here one decade's Landsat 5 data is used to test the proposed method. But it should be noted that other Landsat imagery such as Landsat 8 is also applicable to the proposed method. The analysis is based on the Landsat 5 top-of-atmosphere (TOA) reflectance image collections available from the Google Earth Engine (http://earthengine.google.org), collected originally by USGS/EROS (http://landsat.usgs.gov/). Given that the presence of cloud and terrain shadows may lead to misclassification of water surfaces due to the similarity in reflectance characteristics (Xu, 2006; Verpoorter et al., 2012; Feyisa et al., 2014), the interference observations, including clouds, cloud shadows, snow and ice, are masked mission of the European Space Agency for global land observation. The Sentinel-2A and -2B 
is acquiring imagery every 10 days (every 5 days with the twin satellites together). The spatial resolution is $10 \mathrm{~m}$ in the visible and broad NIR bands, and $20 \mathrm{~m}$ for the red edge, narrow NIR, and SWIR bands. Here, all available Sentinel-2 for the test area is used to test the proposed method on extracting rivers with small widths. The analysis is based on the Sentinel-2 level-1C TOA products available from the Google Earth Engine. The observations affected by clouds are masked according to the flags of Sentinel-2 QA band. Bands at $20 \mathrm{~m}$ resolution are resampled to $10 \mathrm{~m}$ using nearest neighbor method before the bands are stacked for subsequent interpretation.

All of the available Landsat $5 \mathrm{TM}$ datasets are collected for the three study sites chosen in the current study, including the Dongliao Basin, East Tiaoxi Basin, and Hanbei Basin, China (which will be further introduced in Section 3). A total of 618 Landsat images are available and collected, as summarized in Table 1. After the interference observations/pixels are excluded, there are about 50 reserved observations on average for each of the three study areas for the period between 2000 and 2010. From Table 1, it is evident that autumn has the largest number of effective observations whilst winter has the least. Apart from above three study sites, Eden Catchment, UK is also selected as an extra site because most of the river segments in the catchment is less than $30 \mathrm{~m}$ wide and the rivers are not well captured by the Landsat datasets. All of the available Sentinel-2 datasets are collected for the Eden Catchment. A total of 745 Sentinel-2 images are available, as summarized in Table 1. After the interference observations/ pixels are excluded, there are 467 reserved observations on average. 
Table 1. Number of processed images. The reserved observations are obtained by subtracting the interference observations from the raw observations.

\begin{tabular}{|c|c|c|c|c|c|c|c|c|c|c|c|c|}
\hline \multirow{2}{*}{ Test basins } & \multirow{2}{*}{ Satellite } & \multirow{2}{*}{ ID (path-row for Landsat) } & \multicolumn{2}{|c|}{ Spring } & \multicolumn{2}{|c|}{ Summer } & \multicolumn{2}{|c|}{ Autumn } & \multicolumn{2}{|c|}{ Winter } & \multicolumn{2}{|c|}{ Total } \\
\hline & & & Raw & Reserved & Raw & Reserved & Raw & Reserved & Raw & Reserved & Raw & Reserved \\
\hline Dongliao & Landsat & $119-30$ & 35 & 16 & 34 & 13 & 39 & 15 & 35 & 11 & 143 & 55 \\
\hline \multirow[t]{2}{*}{ East Tiaoxi } & Landsat & $119-39$ & 28 & 12 & 23 & 9 & 33 & 15 & 29 & 12 & 113 & 48 \\
\hline & Landsat & $123-39$ & 26 & 8 & 35 & 16 & 41 & 19 & 28 & 7 & 130 & 50 \\
\hline \multirow[t]{2}{*}{ Hanbei } & Landsat & $124-38$ & 27 & 13 & 34 & 15 & 30 & 12 & 23 & 8 & 114 & 48 \\
\hline & Landsat & $124-39$ & 26 & 13 & 31 & 14 & 36 & 14 & 25 & 12 & 118 & 53 \\
\hline Eden & Sentinel & T30UWG, T30UWF, T30UVF & 167 & 49 & 158 & 57 & 224 & 44 & 196 & 63 & 745 & 213 \\
\hline
\end{tabular}

170 


\subsubsection{Random Forest Model}

Mapping water surfaces from multiple images is a complicated task and need to consider and analyze a variety of water signals in spectral response caused by water turbidity and bottom sediments. Herein, a Random Forest model based on a set of predictor variables is developed to extract water surfaces. Random Forest modelling is an ensemble classification technique (Breiman, 2001) and has been extensively used for classification of RS data (e.g. Hudak et al., 2008; Yu et al., 2011; Rodriguez-Galiano et al., 2012). Random Forest models better recognize regional differences in threshold values than the traditional index thresholding methods (Tulbure et al., 2016). Random Forest models do not depend on data distribution assumptions and can make accurate predictions without overfitting data. They have been increasingly used in water surface extraction as a favorable alternative to the traditional statistical approaches (e.g. Malinowski et al., 2016; Schaffer-Smith et al., 2017; Veh et al., 2018).

Random Forest model is composed of a set of classification trees, each of which grows from a random subset of training samples and randomly permuted explanatory variables. The classification trees may grow to a maximum number without pruning and the final classifications are determined by the majority vote of the trees in the forest. The explanatory variables for Landsat datasets in the Random Forest model include Top-Of-Atmosphere (TOA) reflectance for every spectral band, brightness temperature, vegetation indices, and water indices (Table 2). TOA reflectance and brightness temperature are obtained by normalizing the target imagery to remove the unwanted effects created by the variation of sun angle and earthsun distance. The vegetation indices include the Normalized Difference Vegetation Index (NDVI) and the Enhanced Vegetation Index (EVI). NDVI is chlorophyll sensitive and can be used to identify terrestrial vegetation conditions (Tucker, 1979) while EVI is developed to optimize the vegetation signal in high biomass regions, de-couple canopy background signal, and reduce atmosphere influences (Huete et al., 2002). Water indices include the Normalized Difference Water Index (NDWI, McFeeters, 1996), Modified NDWI (MNDWI, Xu, 2006), and Normalized Difference Moisture Index (NDMI, Gao, 1996). NDWI is developed to enhance the response of open water features over the soil and terrestrial vegetation features. MNWI substitutes the middle infrared band for the near infrared band used in the NDWI to enhance water features and remove the noises from other land types. NDMI can be used to effectively 
201 detect vegetation water content. For Sentinel-2 datasets, the explanatory variables include TOA

202 reflectance for the visible bands and 5 difference indices as listed in Table 2. 
Table 2. The explanatory variables of Landsat 5 data used in Random Forest models.

\begin{tabular}{ll}
\hline Explanatory variables & Citation \\
\hline TOA1 & (Chander et. al., 2009) \\
TOA2 & \\
TOA3 & \\
TOA4 & \\
TOA5 & (Tucker, 1979) \\
TOA7 & (Huete et. al., 2002) \\
Brightness temperature & (McFeeters, 1996) \\
Normalized Difference Vegetation Index $(\mathrm{NDVI})=(\mathrm{TOA} 4-\mathrm{TOA} 3) /(\mathrm{TOA} 4+\mathrm{TOA} 3)$ & $(\mathrm{Xu}, 2006)$ \\
Enhanced Vegetation Index $($ EVI $)=2.5 *(\mathrm{TOA} 4-\mathrm{TOA} 3) /(\mathrm{TOA} 4+6 * \mathrm{TOA} 3-7.5 *$ TOA1 + 1) & $($ Gao, 1996) \\
Normalized Difference Water Index $(\mathrm{NDWI})=(\mathrm{TOA} 2-\mathrm{TOA} 4) /(\mathrm{TOA} 2+\mathrm{TOA} 4)$ & \\
The Modified Normalized Difference Water Index $(\mathrm{MNDWI})=(\mathrm{TOA} 2-\mathrm{TOA} 5) /(\mathrm{TOA} 2+\mathrm{TOA} 5)$ & \\
Normalized Difference Moisture Index $(\mathrm{NDMI})=(\mathrm{TOA} 4-\mathrm{TOA} 5) /(\mathrm{TOA} 4+\mathrm{TOA} 5)$ & \\
\hline
\end{tabular}


In this work, the Random Forest model is trained using a set of training data of water and non-water features that is manually selected from $5 \sim 6$ tiles for each of the four test basins. Different types of water surfaces are characterized within the same training class according to the previous studies (Tulbure et a., 2016; Schaffer-Smith et a., 2017). Training samples are selected from images acquired at different times to account for seasonal variations across both wet and dry years. The training samples are selected via visual interpretation of satellite images to represent different types of water surfaces (i.e. rivers, lakes and reservoirs), and a variety of non-water covers including various landscapes and vegetation covers across the test basins. We use a total of 1,644 water pixels and 1,450 non-water pixels across the Dongliao Basin, 405 water pixels and 362 non-water pixels across the East Tiaoxi Basin, 525 water pixels and 389 non-water pixels across the Hanbei Basin, and 1053 water pixels and 564 non-water pixels across the Eden Catchment for training purpose. The data obtained from each of the training pixels includes TOA reflectance of each band and band combinations. The training data is then used to drive and train the Random Forest model. This part of the work can be achieved in Google Earth Engine, which offers the access to not only remote sensing data on a global scale but also substantial power of Google's cloud computing.

\subsection{Calculation of River Presence Possibility}

After mapping the water surfaces, the two key steps of extracting river networks using the proposed EMID method are to (1) calculate the river presence possibility, and (2) search the best river paths (section 2.3). Using the Landsat/sentinel imagery and the Random Forest model, the location and extent of water surfaces are mapped to calculate the water-occurrence frequency $(W f)$ at each pixel, which is defined by

$$
W f_{i}=\frac{\sum_{j=1}^{N} W_{i, j}}{N_{i}} * 100
$$

where $W_{i, j}$ is water surface classification ( 1 for water surface and 0 for non-water surface) at pixel $i$ of imagery scene $j ; N_{i}$ is the total number of valid observations available at pixel $i$. The water-occurrence frequency (i.e. the number of times being flagged as water surface divided by the total number of valid observations) is computed using the water detection results and total valid observations. 
Higher frequency implies larger possibility that a stream pixel is present (river presence possibility), and subsequently lower cost for river centerline to traverse the specific location/ pixel (cost score value). Thus, the cost score value $C_{i}$ of pixel $i$ is calculated by

$$
C_{i}=\left(100 \%-W f_{i}\right)^{a}
$$

where $C_{i}$ is the indicator of the cost of river centerline traversing pixel $i$, with $a(>1)$ being a constant coefficient. An exponential function is adopted in order to increase the cost of a river course passing through a pixel with low water-occurrence frequency and $a=2$ is recommended to increase the cost variation between pixels with different water-occurrence frequency. The results of river extraction are insensitive to $a$ according to our subsequent analysis.

\subsection{Best River Path Searching}

After river presence possibility/cost is calculated in each of the pixels to produce a cost image, the best centerline paths may be traced out for the river networks. With the cost score at each pixel indicating the cost/possibility of a river traversing that specific pixel, the problem of finding the best river path is equivalent to detecting and linking the pixels with minimum cumulative cost. The starting point (i.e., the watershed outlet or the most downstream point) and ending point (i.e., the most upstream point) of a river path can be manually specified.

This best river path searching procedure/algorithm may be better explained using a simple example as illustrated in Fig. 2, which involves finding a minimum-cost path connecting two points, i.e. the starting point $(\mathrm{S})$ at $(0,0)$ and the ending/goal point $(\mathrm{G})$ at $(2,2)$. The steps of searching for the minimum-cost path are explained as follows:

1) Obtain the cost image for study area (Fig. 2(a)).

2) Assign infinity as the value of the first minimum path image (MPI, Fig. 2(c)) and set $\mathrm{MPI}_{2}$ (see Fig. 2(d)) equal to $\mathrm{MPI}_{1}$, except for point/pixel S, which retains its pixel value as specified in the cost image.

3) Compare $\mathrm{MPI}_{\mathrm{i}}$ with $\mathrm{MPI}_{\mathrm{i}+1}(\mathrm{i} \geq 1$ ) and identify those corresponding pixels with different values to set D (see the pixel points in green in Fig. 2(d), Fig. 2(f) and Fig. 2(j)). For example, $\mathrm{MPI}_{2}$ (Fig. 2(d)) is compared with $\mathrm{MPI}_{3}$ (Fig. 2(f)) to obtain the set D including points with coordinates $(0,1),(1,0)$, and $(1,1)$. 
4) For each pixel $P_{j}$ (pixel points in blue in Fig. 2) in set D, examine each of its immediate neighboring pixels $\mathrm{P}_{\mathrm{A}}$ and calculate the cumulative cost as follows:

$$
\text { when } \mathrm{j}=1 \text {, }
$$

$$
\mathrm{MPI}_{\mathrm{i}+2, \mathrm{j}}\left(\mathrm{P}_{\mathrm{A}}\right)=\mathrm{MPI}_{\mathrm{i}+1}\left(\mathrm{P}_{\mathrm{D}}\right)+\alpha^{*} \operatorname{Cost}\left(\mathrm{P}_{\mathrm{A}}\right)
$$

when $\mathrm{j}>1$,

$$
\operatorname{MPI}_{\mathrm{i}+2, j}\left(\mathrm{P}_{\mathrm{A}}\right)=\operatorname{MPI}_{\mathrm{i}+2, j-1}\left(\mathrm{P}_{\mathrm{D}}\right)+\alpha^{*} \operatorname{Cost}\left(\mathrm{P}_{\mathrm{A}}\right)
$$

where $\alpha=1$ when $\mathrm{P}_{\mathrm{A}}$ and $\mathrm{P}_{\mathrm{D}}$ are direct orthogonal neighbors, and $\alpha=\sqrt{2}$ when $\mathrm{P}_{\mathrm{A}}$ and $\mathrm{P}_{\mathrm{D}}$ are diagonal neighbors in order to reflect the extra stream distance between them.

5) Set MPI ${ }_{i+2,1}=\min \left(\mathrm{MPI}_{i+2,1}, \mathrm{MPI}_{i+1}\right)$ if $\mathrm{j}=1$ or MPI $\mathrm{i}_{\mathrm{i}+2, j}=\min \left(\mathrm{MPI}_{\mathrm{i}+2, j}, \mathrm{MPI}_{\mathrm{i}+2, \mathrm{j}-1}\right)$ if $\mathrm{j}>1$, i.e., only the smaller value of each calculation is reserved (the pixel points in red in Fig. 2).

6) Repeat steps 4 and 5 until each pixel $P_{D}$ in set $D$ is checked and all MPI ${ }_{i+2}$ are created, such as $\mathrm{MPI}_{3}$ (Fig. 2(f)), $\mathrm{MPI}_{4}$ (Fig. 2(j)) and $\mathrm{MPI}_{5}$ (Fig. 2(1)).

7) Repeat steps 3 to 6 until the current MPI is equal to the previous MPI.

8) Trace back through the current MPI from G to $S$ to extract the minimum-cost path, such as the path indicated by the arrows in Fig. 2(1).

By following these steps, continuous river paths are traced out and connected networks can be reconstructed in the targeted domain. 


\begin{tabular}{|c|c|c|}
\hline 3 & 8 & 4 \\
\hline 2 & 10 & 4 \\
\hline 4 & 6 & 7 \\
\hline
\end{tabular}

(a) Cost

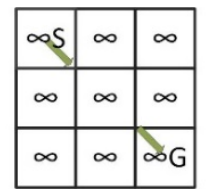

(c) $\mathrm{MPI}_{1}$

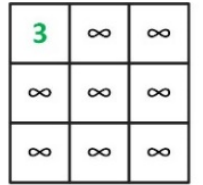

(d) $\mathrm{MPI}_{2}$

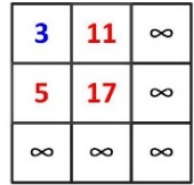

(e) $\mathrm{MPI}_{3,1}$

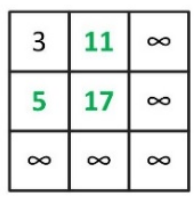

(f) $\mathrm{MPI}_{3}$

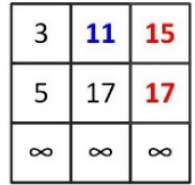

(g) $\mathrm{MPI}_{4,1}$

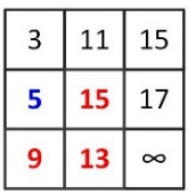

(h) $\mathrm{MPI}_{4,2}$

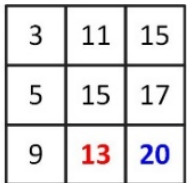

(k) $\mathrm{MPI}_{5,1}$

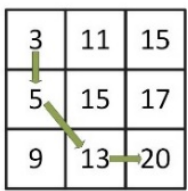

(1) $\mathrm{MPI}_{5}$

(b) Coordinate

\begin{tabular}{|l|l|l|}
\hline 3 & 11 & 15 \\
\hline 5 & 15 & 17 \\
\hline 9 & 13 & 25 \\
\hline
\end{tabular}

(i) $\mathrm{MPI}_{4,3}$

\begin{tabular}{|l|l|l|}
\hline 3 & 11 & 15 \\
\hline 5 & 15 & 17 \\
\hline 9 & 13 & 25 \\
\hline
\end{tabular}

(j) $\mathrm{MPI}_{4}$

Fig. 2. A simple example of finding the best river path using the proposed optimization algorithm.

\subsection{Result Evaluation Methods}

This section introduces the methods adopted to evaluate the results and compare with other river extraction approaches.

\subsubsection{Comparing with Other Methods}

286 In order to evaluate the performance of the proposed river extraction method, existing DEMbased methods and RS-based methods are selected for comparison. For the DEM-based methods, the classical D8 method (O'Callaghan \& Mark, 1984) and multiple flow direction method (MFD, Holmgren, 1994; Jasiewicz \& Metz, 2011) are selected. The D8 method extracts a river channel by assigning a pointer from each cell to one of its eight neighboring cells, in the direction of steepest descent. The MFD method distributes the flow in a pixel to all of the neighboring pixels that have lower elevations and tends to improve the D8 method by avoiding concentration to distinct lines (Seibert \& McGlynn, 2007). 
For RS-based methods, two of the state-of-the-art morphological methods, i.e., the multiscale singularity approach (Isikdogan et al., 2015) and RivWidth approach (Pavelsky \& Smith, 2008) are adopted to compare with the proposed EMID method. The singularity approach has been successfully applied to extract river networks in North America using singularity index and Modified Normalized Difference Water Index (MNDWI) (refer to Table 2) from RS imagery. The widely reported RivWidth method adopts the techniques of edge detection and boundary definition to derive river centerlines.

Herein, global open-source DEMs are used to support the implementation of the selected DEM-based methods, including the SRTM (Shuttle Radar Topographic Mission) DEM (Rabus et al., 2003; Farr et al., 2007), ASTER (Advanced Spaceborne Thermal Emission and Reflection Radiometer) DEM (Fujisada et al., 2012), and MERIT (Multi-Error-Removed Improved-Terrain) DEM (Yamazaki et al., 2017). The ASTER DEM and SRTM DEM are currently the most popular topographic data. MERIT is an improved DEM derived from the SRTM DEM after removing a number of key errors and has a better vertical accuracy and has been recently used to develop the global raster hydrography dataset MERIT Hydro (Yamazaki et al., 2019), which can be vectorized to produce the global river centerlines (Lin et al., 2019). So, a total of six sets of results from DEM-based methods (D8-ASTER, D8-SRTM, D8-MERIT, MFD-ASTER, MFD-SRTM and MFD-MERIT) will be used for comparison with the current EMID method.

With respect to the two selected RS-based methods, the singularity approach is implemented through the Python package RivaMap, developed by Isikdogan et al. $(2015,2017)$. The model parameters are set according to the developers' recommendations. The RivWidth approach has been used by Allen \& Pavelsky (2018) to build a database of global river networks from Landsat imagery, i.e., the GRWL database (Global River Widths from Landsat). The GRWL database contains all of the global rivers with a width of $\geq 30 \mathrm{~m}$ at the mean annual discharge condition. The GRWL database is directly adopted in this work to compare with the results of large rivers obtained using alternative methods.

\subsubsection{Evaluation Metrics}


To quantitatively evaluate the results, the river extraction outcomes may be classified as true positive (TP), false positive (FP), and false negative (FN) (Orlandini et al., 2011). TP is defined when a correct prediction is made, i.e., a pixel traversed by a stream centerline in real world is correctly detected. FP occurs when a pixel is incorrectly detected as stream pixel, i.e., the actual stream centerline does not traverse the identified pixel. FN represents the case when an actual stream pixel is not identified. Based on these definitions, the quality of river extraction results and hence the performance of the proposed method may be evaluated using two error metrics, i.e. false positive rate $(F P R)$ and false negative rate $(F N R)$, defined as follows:

$$
\begin{aligned}
& F P R=\frac{N_{F P}}{N_{F P}+N_{T P}} \\
& F N R=\frac{N_{F N}}{N_{F N}+N_{T P}}
\end{aligned}
$$

where FPR measures the error of commission, i.e., predicting river streams in the wrong place; FNR represents the error of omission, i.e., omitting the places where river streams are actually located; and $N_{T P}, N_{F P}$ and $N_{F N}$ denote the numbers of true positive, false positive and false negative predictions, respectively. A reliable river extraction method is expected to produce results with low FPR and low FNR that are both low.

In addition to $F P R$ and $F N R$, another useful error metric for evaluating the performance of a river extraction method is the Euclidean distance $d_{k}$, which is defined as the distance between the center of predicted stream pixel $(C$, through which the predicted stream centerline passes) and the closet point $(P)$ at the reference stream centerline (Moretti \& Orlandini, 2018):

$$
d_{k}=\sqrt{\left(x_{k}^{(c)}-x_{k}^{(p)}\right)^{2}+\left(y_{k}^{(c)}-y_{k}^{(p)}\right)^{2}}
$$

where $k=1, \ldots, M$ is the index of the stream pixels and $M$ is the total number of pixels defining the predicted river stream centerline. The mean Euclidean distance error $(E D)$ can be then calculated using

$$
E D=\frac{1}{M} \sum_{k=1}^{M} d_{k}
$$

To apply the above error metrics to evaluate the performance of a river extraction method, ground-truth data is needed. Herein, we use the Google Earth platform to manually map out the layout and location of river networks to create reference data for areas without field observation/surveyed river data. The high spatial resolution images from the Google Earth 
platform provide an alternative way of deriving high-precision datasets for river networks (Chen et al., 2018), owing to their low horizontal error, free availability and global coverage (Mohammed et al., 2013; Pulighe et al., 2016). The detail of the adopted imagery from Google Earth is summarized in Table. S1 of the Supporting Material. The imagery provided by Digital Globe, with a spatial resolution of is $0.65 \mathrm{~m}$, is mainly adopted because its acquisition period is roughly consistent with the Landsat imagery considered in this work. The void areas that the Digital Globe imagery does not cover is supplemented by the imagery from CNES/Airbus, whose spatial resolution is $1.5 \mathrm{~m}$. In order to obtain accurate and complete river networks from Google Earth, the imagery acquired in the dry seasons is used as benchmarks to vectorize the wide rivers and the imagery observed in the wet seasons is adopted for narrow rivers. Examples of the rivers extracted from the Google Earth platform can be found in Fig. S1 of the Supporting Material. Those large water surfaces connected to the river networks, such as lakes and reservoirs, are excluded from the analysis in order to ensure the products are comparable with the predicted river centerlines.

\section{STUDY AREAS}

Four test basins with low-relief landscapes but different hydrological characteristics and river morphology (Fig. 3) are chosen to validate and evaluate the proposed river extraction method. Dongliao Basin has a natural meandering course due to channel erosion and morphological change, leading to high sinuosity. Hanbei Basin is characterized by two parallel man-made channels. East Tiaoxi Basin forms a typical plain river network, which is characterized by the distribution of the crisscrossed rivers. Eden Catchment is featured with narrow plain rivers with small width and high sinuosity. These various basin characteristics impose different challenges in accurately detecting and depicting the river networks, and therefore the four selected basins provide representative case studies to demonstrate the strengths and limitations of the proposed method, which will be introduced in detail in the following sub-sections. 

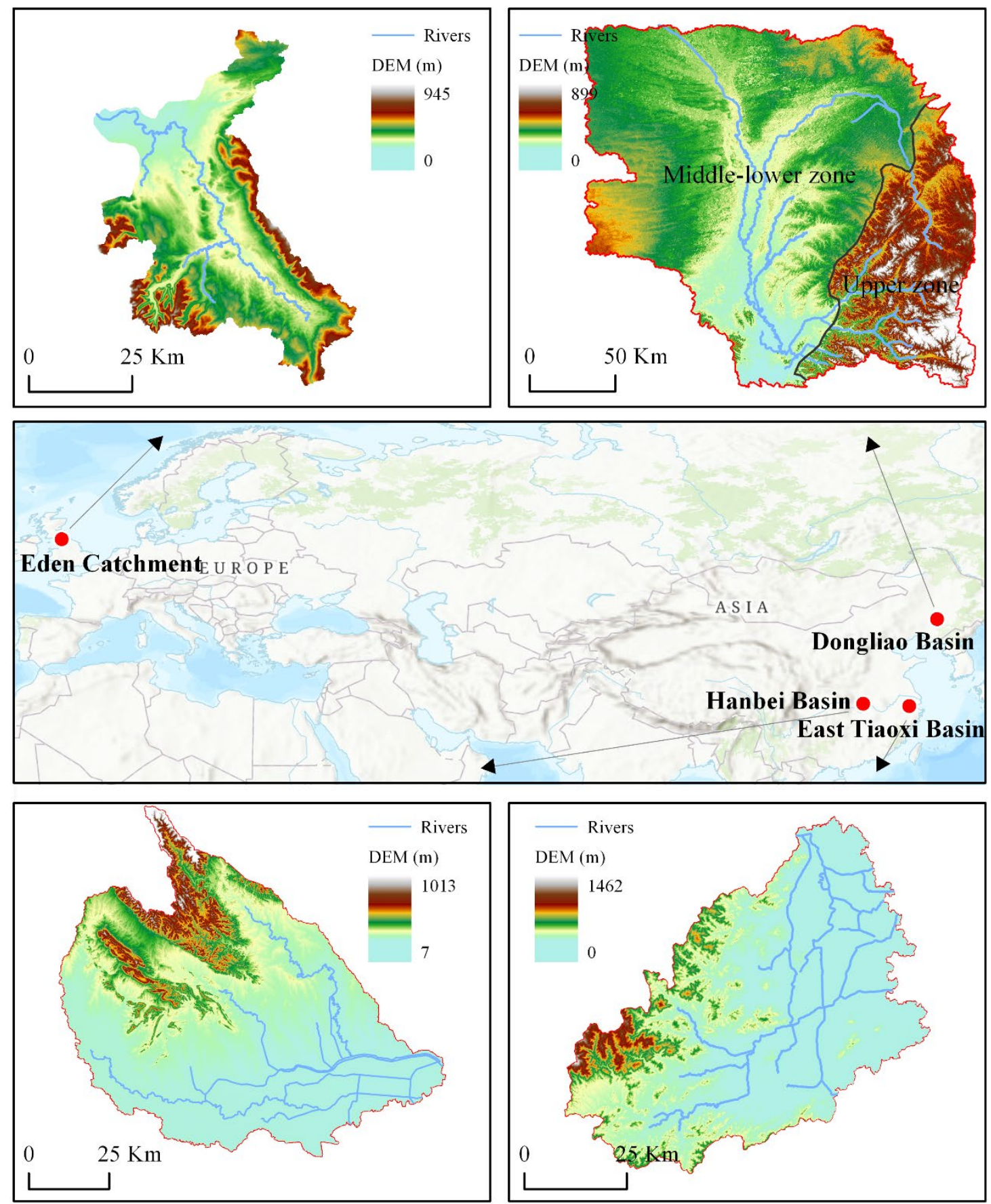

Fig. 3. The four test basins and the river networks. The river network in the Eden

377 Catchment is obtained from Ordnance Survey (the national mapping agency for the Great

Britain); River networks of Dongliao Basin, East Tiaoxi Basin, and Hanbei Basin are

379 manually extracted from the Google Earth imagery (the adopted imagery is summarized in

Table. S1 of the Supporting Material). 


\subsection{Dongliao Basin}

Dongliao Basin is located between $42^{\circ} 09^{\prime} \sim 44^{\circ} 09^{\prime} \mathrm{N}$ and $122^{\circ} 20^{\prime} \sim 125^{\circ} 14^{\prime} \mathrm{E}$ and has an area of $11,306 \mathrm{~km}^{2}$. The basin is characterized with a semi-humid monsoon climate with four distinctive seasons, influenced by the Siberia high pressure and Pacific low pressure. The mean annual rainfall varies from $700 \mathrm{~mm}$ upstream to $450 \mathrm{~mm}$ downstream, and $75 \%$ of the annual precipitation occurs in the period between June and September (Zhang et al., 2012). According to its topographical features and valley shape, the basin may be roughly divided into two zones. The upper zone is covered by low hilly areas with an altitude from $200 \mathrm{~m}$ to $600 \mathrm{~m}$ while the middle-lower zone located downstream of Erlongshan Reservoir is mainly the plain area with an altitude from $50 \mathrm{~m}$ to $200 \mathrm{~m}$. The river courses in the middle-lower zone are typically meandering with high sinuosity. Due to relatively unconstrained floodplains and active morphodynamical changes, the river courses are prone to horizontal migration. Therefore, it is more challenging to accurately extract the river networks in the middle-lower Dongliao Basin, which is selected to demonstrate the performance of the proposed river extraction method.

\subsection{East Tiaoxi Basin}

Located between $30^{\circ} 07^{\prime} \sim 30^{\circ} 55^{\prime} \mathrm{N}$ and $119^{\circ} 26^{\prime} \sim 120^{\circ} 24^{\prime} \mathrm{E}$, the $5,931 \mathrm{~km}^{2}$, the East Tiaoxi Basin drains the $96 \mathrm{~km}$ long East Tiaoxi River and its tributaries. The East Tiaoxi Basin features a typical East Asian monsoon climate, which is warm and humid with four different seasons. The average annual temperature is $15.7^{\circ} \mathrm{C}$ and average rainfall is approximately $1454 \mathrm{~mm}$, with nearly $75 \%$ of the rainfall occurring between April and September (Jin et al., 2018). The basin has an overall higher terrain in the west and the landscape in the east is low and flat with an altitude between $0 \mathrm{~m}$ and $5 \mathrm{~m}$. The eastern basin has developed a typical plain river network system featured with high water surface ratio and crisscrossing rivers and lakes spreading extensively across the region. The small difference in upstream and downstream terrain elevations and high water surface ratio makes the Basin an interesting and challenging case study for accurate detection and depiction of river networks. 


\subsection{Hanbei Basin}

Located between $30^{\circ} 30^{\prime} \sim 31^{\circ} 11^{\prime} \mathrm{N}$ and $112^{\circ} 38^{\prime} \sim 113^{\circ} 57^{\prime} \mathrm{E}$, the $8,655 \mathrm{~km}^{2}$, the Hanbei Basin drains a major tributary of the Hanjiang River (Hanjiang River is the largest tributary of the Yangtze River). The basin is situated in a humid zone of sub-tropic monsoon climatic environment, with an average annual temperature of $16.1{ }^{\circ} \mathrm{C}$ and average annual rainfall of $1077 \mathrm{~mm}$. But the overall rainfall pattern shows high intra-annual and inter-annual variations and $70 \%$ of the precipitation occurs between May and September. The landscape in the Hanbei Basin is mostly flat with a well-developed river system. The $242 \mathrm{~km}$ main river course across the basin has more than 20 branches. Hanbei River has a mean slope of $0.2 \%$ and sinuous course (the river length is about two times of the basin length) (Zhou \& Peng, 2011). The Hanbei Basin can be roughly divided into two zones. The southern zone possesses well-defined water surface and is home to the largest inland enclosed lake (Diaocha Lake) in China. In the northern zone, the $92.6 \mathrm{~km}$ main river course is actually an artificial canal, which was constructed as part of an integrated flood control project in 1969. The artificial canal delivers excess water flow from the upstream low-lying plain to the Hanjiang River to mitigate flood risk. In the 1990s, another artificial canal was constructed, which is parallel to the original canal but approximately $1 \mathrm{~km}$ away. As a result, the Hanbei River presents a unique double channel landscape and the special channel morphology makes the Basin an ideal case to further test the proposed river extraction method in depicting artificial channels.

\subsection{Eden Catchment}

The $2280 \mathrm{~km}^{2}$ Eden Catchment is located between $54^{\circ} 20^{\prime} \sim 55^{\circ} 8^{\prime} \mathrm{N}$ and $2^{\circ} 10^{\prime} \sim 3^{\circ} 10^{\prime} \mathrm{W}$ in Cumbria, North West England, UK. The annual average precipitation is $1183 \mathrm{~mm}$, ranging from less than $650 \mathrm{~mm}$ in the lowland areas to more than $2000 \mathrm{~mm}$ in the uplands. The Catchment contains a variety of landscapes and land uses, with the upland characterized by moorlands and unimproved pastures, and the lower reaches covered mainly by improved pastures. The upland catchment has steep slopes, while the lower reaches are characterized by wide and shallow valleys. In the lower reaches, the flat terrain forms rivers with high sinuosity. According to the field surveyed river data provided by Ordnance Survey (the national mapping agency of the 
435 Great Britain), $62 \%$ of the total length of the main rivers in the lower reaches of the Eden

436 Catchment consists of channels less than $30 \mathrm{~m}$ wide. Thus, the main rivers of $196 \mathrm{~km}$ long are

437 chosen to test the performance of the proposed river extraction method in extracting plain rivers

438 with a width of less than $30 \mathrm{~m}$.

\section{4. RESULTS AND DISCUSSION}

440 In this section, the river extraction results from the proposed EMID method are presented and

441 discussed, where results for water surface mapping will be first introduced.

\section{$442 \quad 4.1$ Extent and Dynamics of Water Surface Areas}

443 Water surfaces are extracted from satellite images using a Random Forest model. The obtained 444 water-occurrence frequency across the Dongliao Basin is presented in Fig. 4(a), showing high 445 spatial variability. The highest water-occurrence frequency, varying from $80 \%$ to $100 \%$, 446 appears in the downstream river streams, reservoirs, lakes and other permanent water bodies. 447 The moderate frequency, ranging from $20 \%$ to $50 \%$, returns to reflect the main river streams 448 and some wetland areas in the upper Basin. The lowest water-occurrence frequency $(<15 \%)$ 449 reflects those small tributary streams and paddy fields. Most of the river streams have water450 occurrence frequency less than $100 \%$ because the widths of these streams at the time when the 451 imagery is acquired may be less than the pixel width of the Landsat imagery $(30 \mathrm{~m})$. Therefore, 452 the capacity of mapping riverine water bodies highly depends on the time of data acquisition 453 and the size (width) of the targeted riverine water bodies (Frazier \& Page, 2000; Handcock et 454 al., 2006; Jiang et al., 2014). 

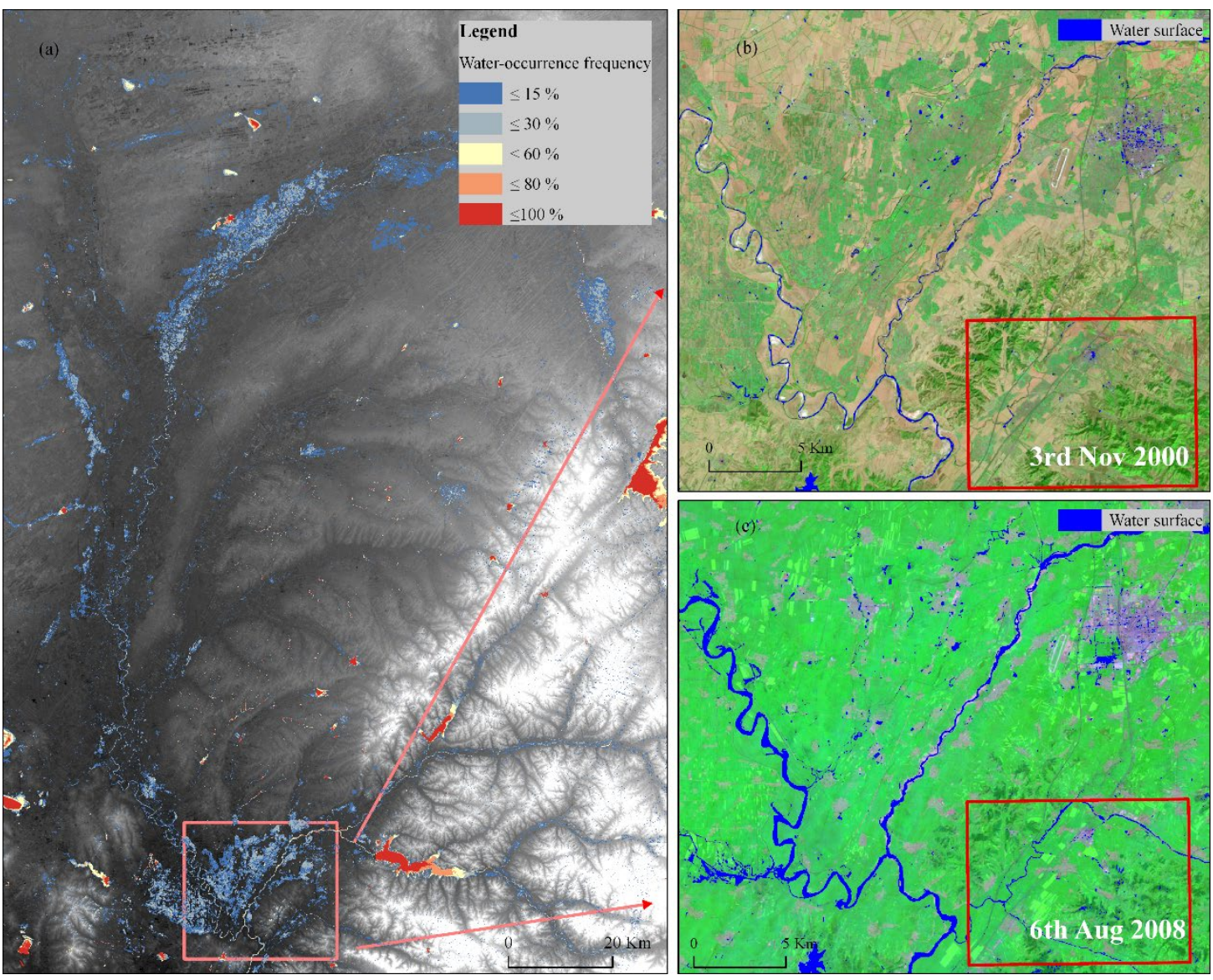

Fig. 4. Extracted water surface areas in the Dongliao Basin: (a) Water-occurrence

frequency map; (b) The water surface area of a dry year (2000) displayed over the

Across the whole Dongliao Basin, small water-occurrence extents have been returned for the year of 2000 (Fig. 4(b)) when a serious drought occurred and the annual precipitation was substantially lower than the long-term average (Yang et al., 2007). The main course of the Dongliao River is among the few river streams that still show occurrence of open water in that year. These yet flowing river streams usually has a width of 1 2 pixels, which effectively trace out the centerlines of riverine water bodies and may be conveniently used to vectorize the river centerline. However, this output may filter out and fail to identify those river streams with smaller stream widths (less than the pixel size of $30 \mathrm{~m}$ ) in the drought years (e.g. the obvious channel network presented inside the red box in Fig. 4(b)). On the contrary, large water- 
occurrence extent occurred in 2008 (Fig. 4(c)), which was a wet year with annual precipitation much higher than the long-term averages. The displayed water surface areas cover more small rivers including some of the intermittent streams (e.g. as indicated by the clear river courses outlined in the red box in Fig. 4(c)). Therefore, mapping surface water dynamics across different years may enable us to detect and connect small and intermittent streams, and to more accurately extract the exact locations of the complete river networks.

Fig. 5 presents the water-occurrence frequency map across East Tiaoxi Basin, which also demonstrates clear spatial variability (Fig. 5(a)). The areas with high-occurrence frequency (> 80\%; plotted in red in Fig. 5) are spatially concentrated, covering the areas with persistent water surface, e.g. major rivers, lakes and reservoirs. In the lower Basin, many fishing ponds exist due to the development of aquaculture (Li et al., 2013) and a lot of paddy fields also spread across the whole area (Su et al., 2014). The water-occurrence frequency map also marks the ponds and paddy fields. The fishing ponds are characterized with moderate water-occurrence frequency of $30 \%$ to $60 \%$, as marked by the yellow color in Fig. 5(c). Rice is transplanted in a mixture of soil and water, and the water/open-canopy phase lasts several weeks after a plant is transplanted (Dong et al., 2015). The water surface of paddy fields is easy to detect during the open canopy phase but will significantly shrink or disappear afterwards. It therefore demonstrates clear temporal variability and is featured with a low water-occurrence frequency of $<15 \%$ (Blue color in Fig. 5(b))).

As clearly seen in Fig. 5(b) and Fig. 5(c), different types of water surface areas co-exist, which include rivers, lakes, floodplains, wetlands, and paddy fields. A major challenge to accurately delineate river networks from RS imagery is to distinguish the permanent water surfaces (e.g. river and lakes) and temporary water bodies (e.g. inundated floodplains, wetlands, and paddy fields). Multi-temporal Landsat imagery can be used to carry out water-occurrence frequency analysis at a relatively high resolution to distinguish different types of water bodies (Yamazaki et al., 2015). Although the permanent and temporary water bodies are not strictly separated in the current study, the water-occurrence frequency analysis effectively provides important priori knowledge and information to detect those pixels where rivers are more likely to pass through. 

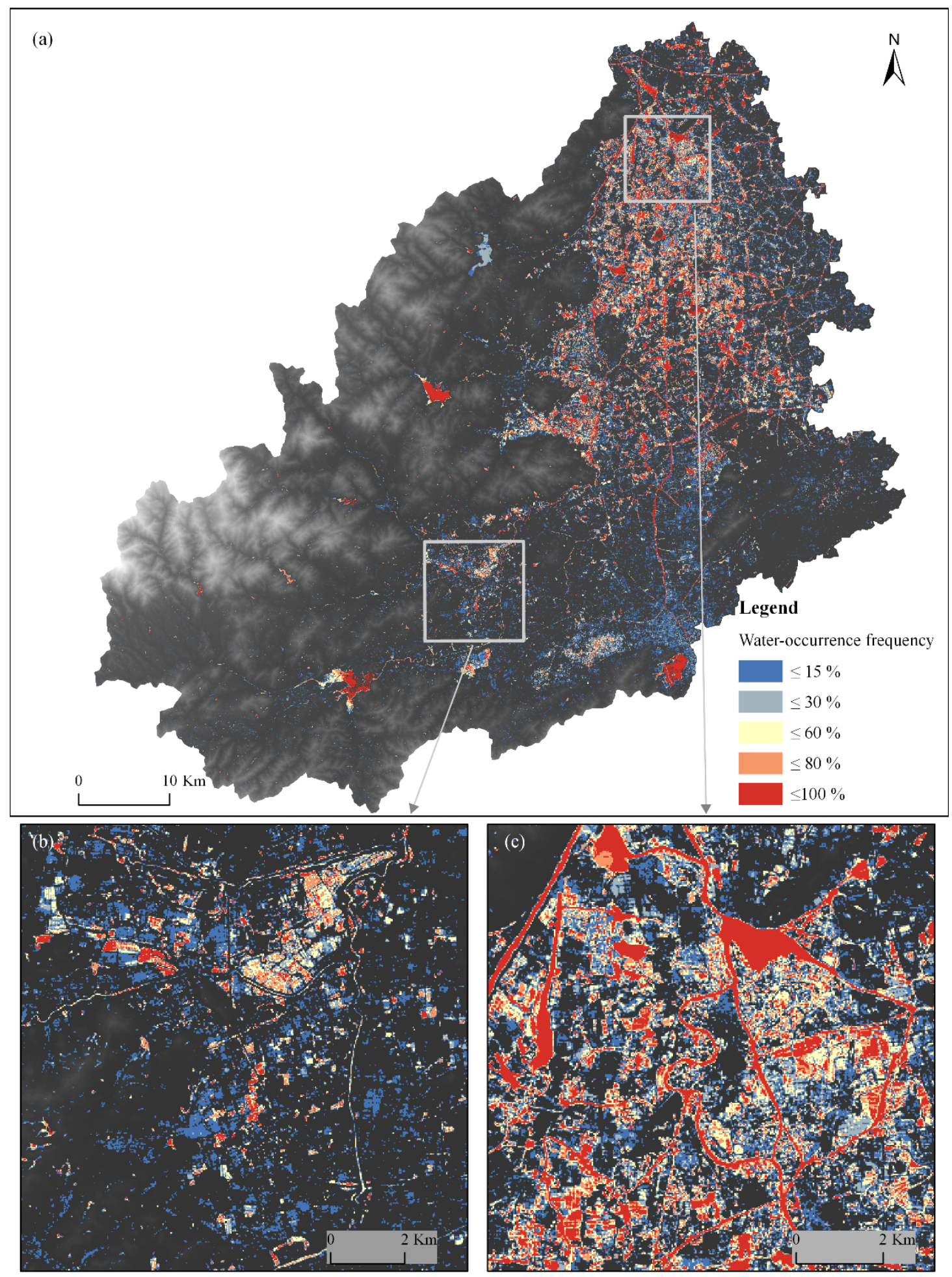

Fig. 5. Water-occurrence frequency maps in the East Tiaoxi Basin: (a) Water-occurrence frequency map across the entire basin; (b) and (c) zoom-in maps. 
504 of large lakes and paddy fields across the entire basin (Deng et al., 2015). The areas with high 505 water-occurrence frequency $(>80 \%)$ cover primarily rivers, lakes and reservoirs, as marked in 506 red in Fig. 6. Paddy fields are scattered across the basin with low water-occurrence frequency $507(<15 \%$; plotted in Blue in Fig. 6). As mentioned in the previous section, Hanbei Basin is home 508 to the Diaocha Lake (Fig. 6(b)) and two parallel artificial channels (Fig. 6(c)). The Diaocha 509 Lake and its connected rivers possess open water surface almost all year around and therefore 510 have relatively high water-occurrence frequency ( $\sim 60 \%)$. In order to accurately derive the river 511 networks, it is also important to separate the river stream pixels from those representing other 512 types of permanent water bodies that are not part of the river networks. For the two parallel 513 artificial channels, whilst they return high water-occurrence frequency as expected, the open 514 area between them $(\sim 1 \mathrm{~km}$ wide $)$ presents moderate frequency $(\sim 20 \%)$ due to regular flood 515 inundation. Clearly, it is also essential to avoid the interference from potential inundated 516 floodplains in the river network delineation practice by distinguishing different types of water bodies using multi-temporal Landsat imagery as mentioned previously. 


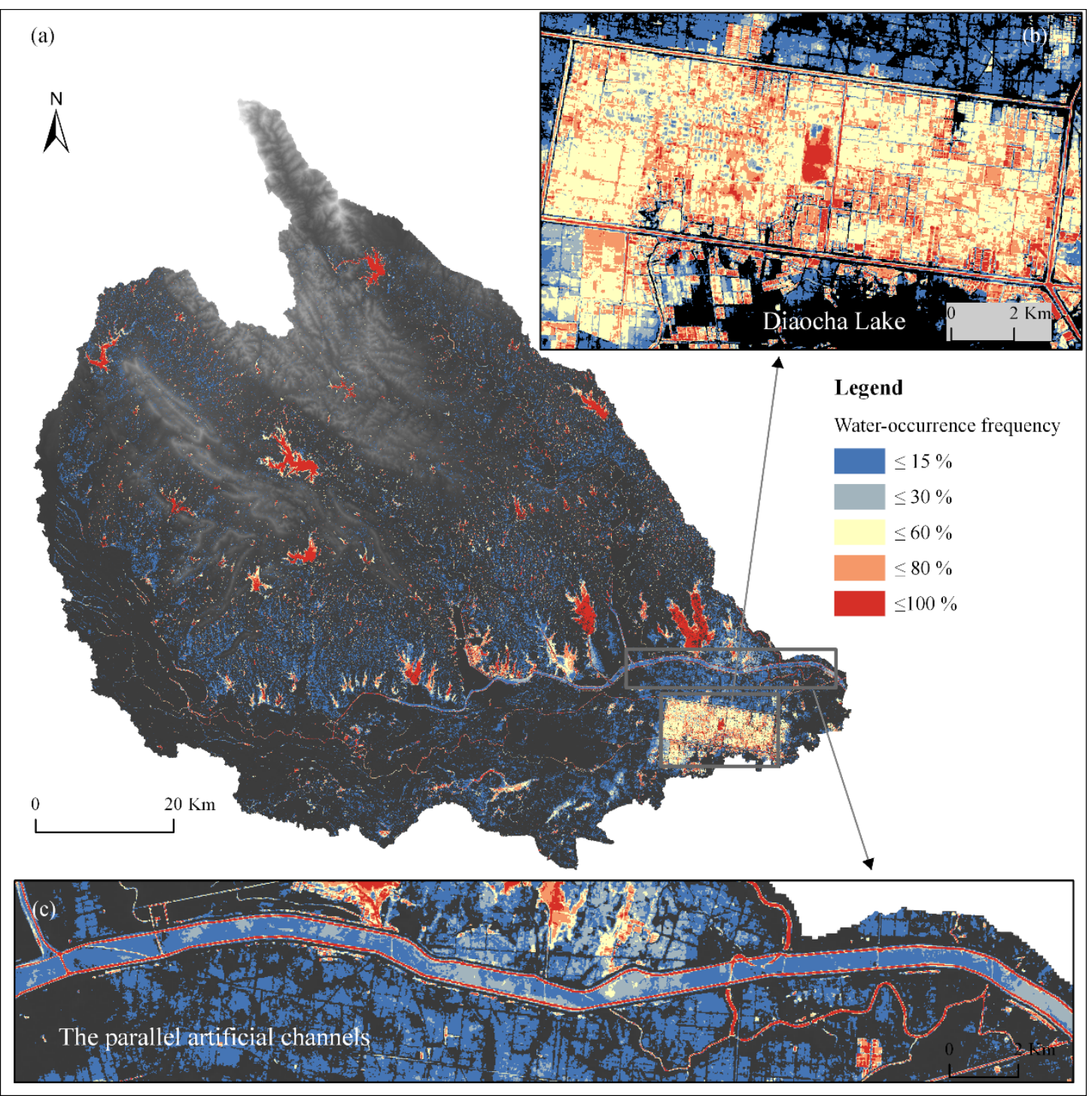

Fig. 6. Water-occurrence frequency maps in the Hanbei Basin: (a) Across the entire

The water-occurrence frequency map for the Eden Catchment is obtained from all of the available Sentinel-2 images acquired between 2015 and 2019. The frequency map is able to 523 identify rivers with bankful width of more than $10 \mathrm{~m}$. Most of the identified river streams have water-occurrence frequency less than $100 \%$ because under normal conditions the width of these 525 streams is less than the pixel width of the Sentinel-2 imagery $(10 \mathrm{~m})$. But these streams can still be identified because high revisit frequency of Sentinel-2 ensures availability of images during

527 flooding periods. During the flooding periods, the river streams are swollen and may be even 528 expanded to inundate the adjacent areas to become wide enough for Sentinel-2 imagery to detect. Obviously, it is the higher resolution and revisit frequency of Sentinel-2 imagery that 
make it possible to identify these small river streams in the Eden Catchment.

531

532

533

534

535

536

537

538

539

540

541

542

543

544

545

546

547

548

549

550

551

552

553

554

555

556

557

558

\subsection{River Network Extraction Results}

Based on the above water-occurrence frequency results, the river networks in the four test basins are extracted using the proposed EMID method and compared with the results obtained using alternative approaches. In EMID, the river presence possibility/cost value is calculated based on the water-occurrence frequency. The starting point (i.e., the watershed outlet or most downstream point) and goal point (i.e., the most upstream point) of each river within the test basins are specified according to the high resolution google earth satellite imagery. We trace each river from the watershed outlet in the opposite direction of the river flow and stop where the river features cannot be significantly identified anymore. There are 17, 19, 25, and 4 goal points identified in the Dongliao Basin, East Tiaoxi Basin, Hanbei Basin, and Eden Basin, respectively. The path between the starting point and goal point of a river is then traced out by detecting and linking a series of pixels with minimum cumulative cost values. All of the rivers are traced out one by one by following the path searching procedure until the complete river networks within the test basin are delineated. Path searching is achieved using MATLAB on a PC installed with a processor of CPU Intel Core i5-8500, $3.00 \mathrm{GHz}$ with 16GB RAM. The run time is $3 \mathrm{~h} 10 \mathrm{~min}, 24 \mathrm{~min}, 1 \mathrm{~h} 9 \mathrm{~min}$, and $1 \mathrm{~h} 54$ min for Dongliao Basin, East Tiaoxi Basin, Hanbei Basin, and Eden Basin, respectively.

For the DEM-based methods, the D8 method and MFD method are implemented using the hydrology toolboxes in ArcGIS and the r.stream.extract tool in GRASS GIS, respectively. Given that DEM-based methods routinely define river networks as pixels with drainage areas greater than a threshold value, a small threshold value $\left(10 \mathrm{~km}^{2}\right)$ is adopted in order to identify all potential stream pixels and include all possible river networks. When the RivaMap method is used for the tests, Landsat 5/Sentinel-2 images are selected based on a low threshold of cloud cover (less than 10\%) and visually inspected to ensure each selected image is clear and at adequately high-quality. The derived river networks from each selected imagery are compared and the one covering the most river segments is selected for performance evaluation. The extracted rivers from DEMs and Rivamap are inspected, and only those representing the 'real rivers' as defined by Google Earth or field survey data are reserved in order to make the results 
comparable between different methods.

\subsubsection{Results from the Proposed EMID Method}

The resulting river network maps are first examined visually. Fig. 7 shows the river networks derived from the EMID and alternative methods along with the river networks manually mapped from Google Earth in the Dongliao Basin. As shown in Fig. 7(a) for the entire basin and Fig. 7(b) for the zoom-in area, the stream centerlines extracted using the EMID method (red lines) agree well with those mapped from Google Earth (blue lines), which suggests that the EMID method performs satisfactorily in obtaining the layouts and locations of the river networks in the Basin.

The river extraction results for the East Tiaoxi Basin are shown in Fig. S2 in the Supporting Material. As mentioned before, the basin is characterized by co-existence of abundant permanent water surfaces and temporary water bodies, which inevitably affect the accuracy of delineating river networks. The close agreement between the EMID and Google Earth river networks demonstrates the superior capability of the EMID method in areas with obvious interference of temporary water bodies (Fig. S2(a)).

Fig. 8 presents extracted river networks for the Hanbei Basin, comparing with the reference networks mapped from Google Earth. As shown in Fig. 8(a), although certain false negative results are observed, the stream centerlines extracted using EMID (shown in red lines) match well with the Google Earth references (shown in blue lines). EMID is able to properly extract the complete river networks connected to Diaocha Lake and the two parallel artificial channels (white box in Fig. 8(a)).

The river extraction results for the Eden Catchment are shown in Fig. 9. EMID is found to successfully extract all of the main rivers in the Catchment and the extracted stream centerlines agree well with the field surveyed data. With multi-temporal Sentinel-2 imagery EMID is able to extract rivers with bankful width of more than $10 \mathrm{~m}$ (one Sentinel-2 pixel wide). To compare the results, the Landsat imagery is also used and the results are showed in Fig. S3 of the Supporting Material. As expected, the Landsat imagery is able to capture the rivers with bankful width of more than $30 \mathrm{~m}$ but presents difficulty for narrower rivers. Apart from the limitation of moderate spatial resolution, the inferior performance of the Landsat imagery in depicting 
589 limited valid observations (30\% of all observations).
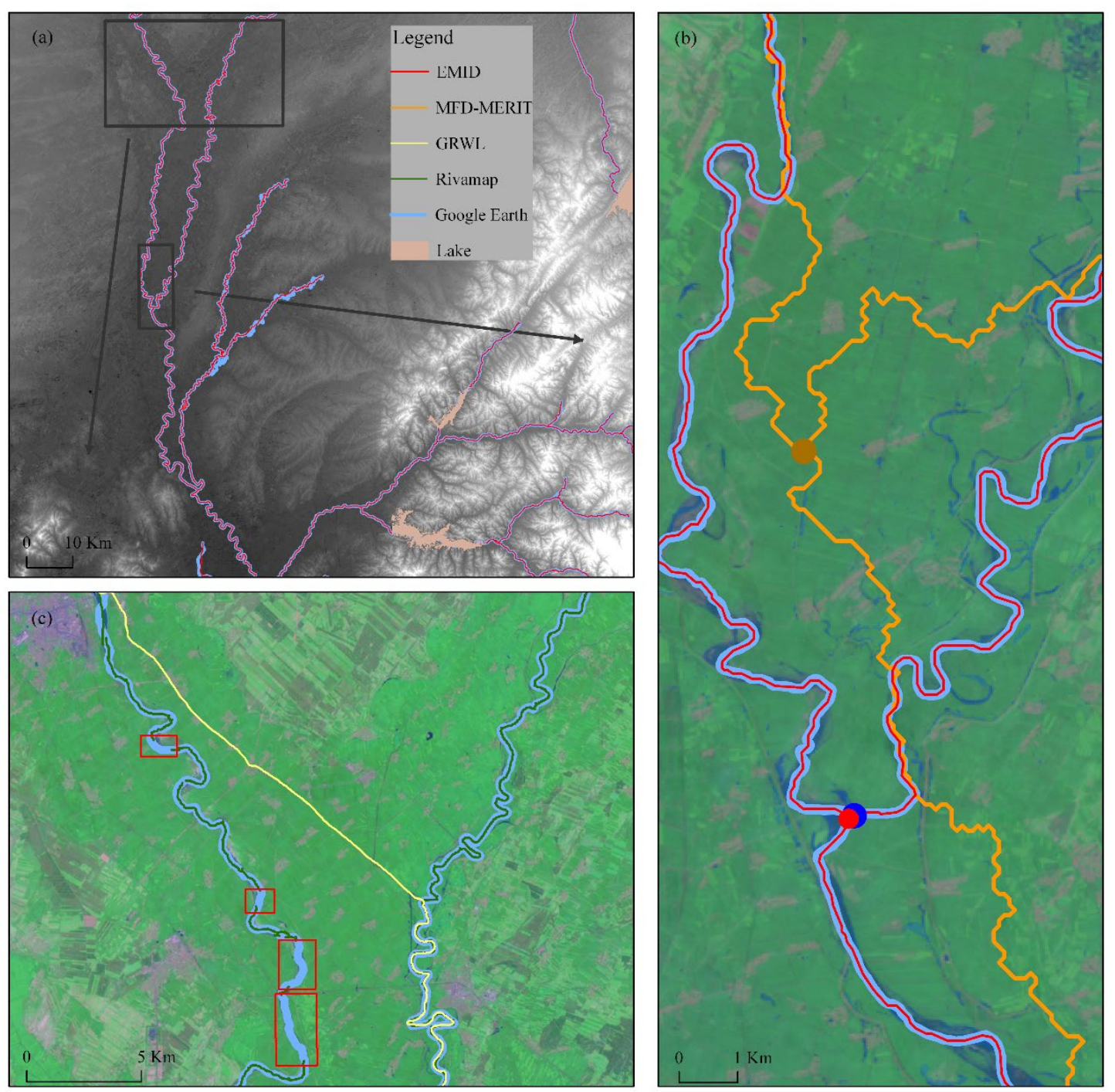

Fig. 7. Comparison between the river networks derived from different methods and the

the entire basin; (b) and (c) Zoom-in areas displayed on the Landsat 5 TM imagery. 

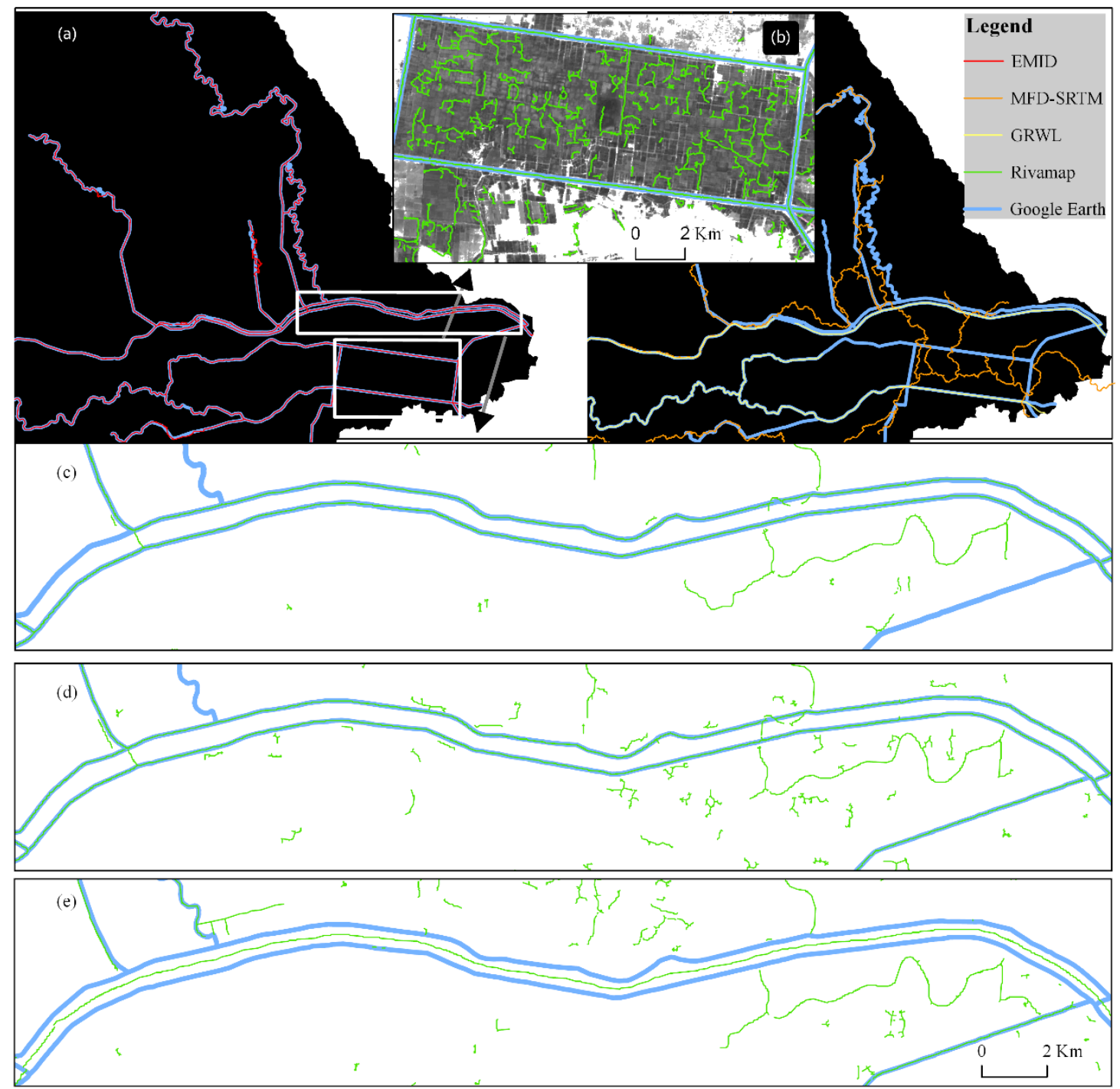

Fig. 8. Comparison between the river networks derived from different methods and the two parallel artificial channels in the dry season; (d) the two parallel artificial channels in the normal season; (e) the two parallel artificial channels in the wet season. 


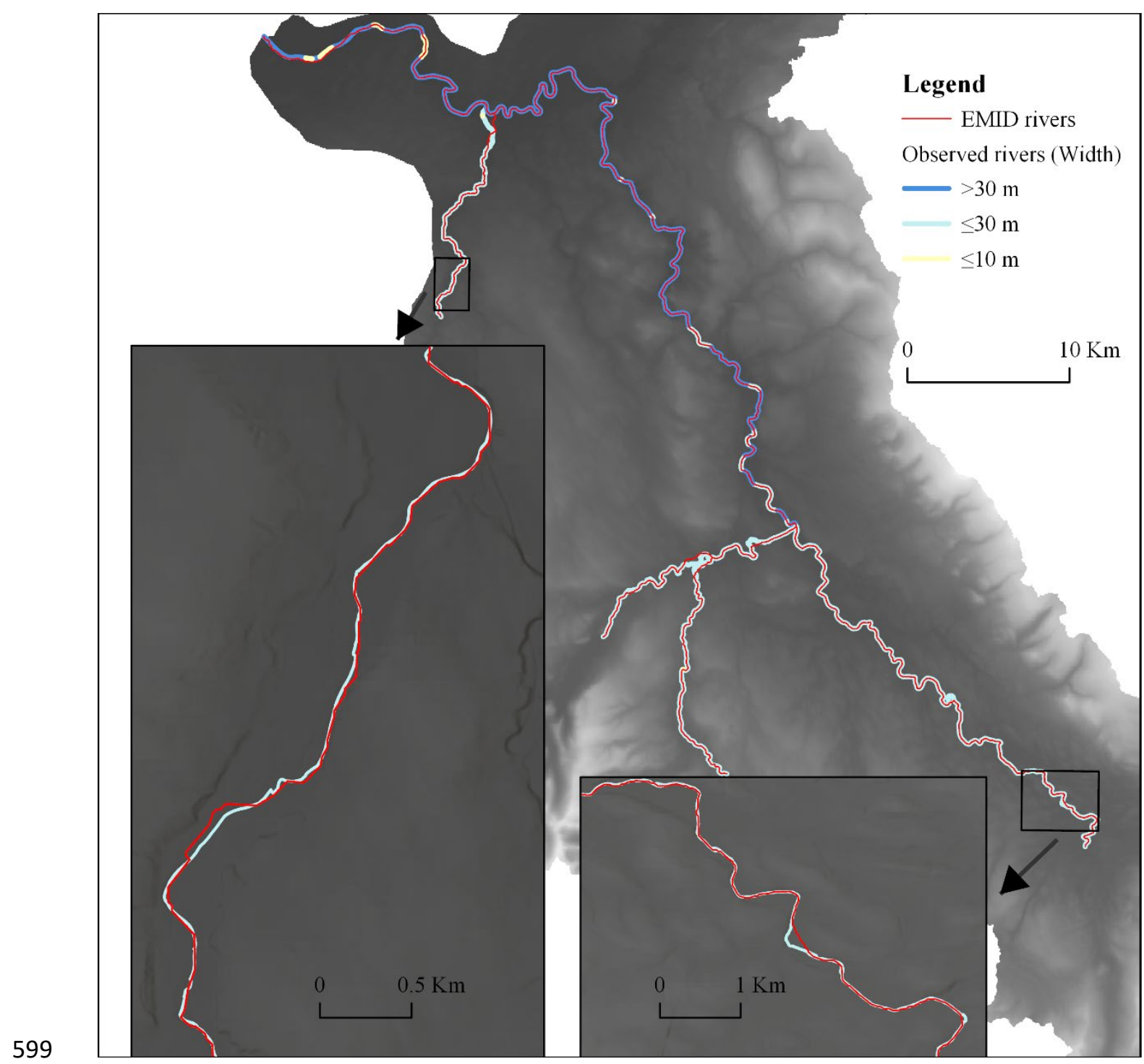

600 Fig. 9. Comparison between the river networks derived from the Sentinel imagery using

The quantitative evaluation indices $F P R, F N R$ and $E D$ are further calculated for the river extraction results obtained from the proposed EMID and alternative methods, which are summarized in Table 3. For study areas using the Landsat imagery including the Dongliao Basin, East Tiaoxi Basin and Hanbei Basin, All of the FPR and FNR errors are calculated to be respectively less than $10 \%$ and $20 \%$, both of which are reasonably low. Meanwhile, all of the $E D$ s are consistently less than $30 \mathrm{~m}$ (one pixel wide on Landsat imagery) across the three test basins (Fig. 10). As for the Eden Catchment which uses the Sentinel-2 imagery as the data source, the calculated FPR, FNR and ED errors are $27 \%, 29 \%$, and $20 \mathrm{~m}$, respectively. 
Table 3. Error metrics of the river network extraction results produced using different data sources or methods.

\begin{tabular}{|c|c|c|c|c|c|c|c|c|c|c|}
\hline \multirow{3}{*}{ Test site } & \multirow{3}{*}{ Error metrics } & \multicolumn{6}{|c|}{ DEM-based method } & \multicolumn{3}{|c|}{ RS-based method } \\
\hline & & \multicolumn{3}{|c|}{$\mathrm{D} 8$} & \multicolumn{3}{|c|}{ MFD } & \multirow{2}{*}{ GRWL } & \multirow{2}{*}{ Rivamap } & \multirow{2}{*}{ EMID } \\
\hline & & ASTER & SRTM & MERIT & ASTER & SRTM & MERIT & & & \\
\hline \multirow{3}{*}{$\begin{array}{c}\text { Dongliao } \\
\text { Basin }\end{array}$} & False positive rate (\%) & 92 & 90 & 78 & 90 & 88 & 76 & 32 & 28 & 9 \\
\hline & False negative rate $(\%)$ & 94 & 91 & 82 & 91 & 90 & 80 & -- & 61 & 17 \\
\hline & Distance error (m) & 916 & 521 & 581 & 956 & 545 & 531 & 184 & 57 & 28 \\
\hline \multirow{3}{*}{$\begin{array}{l}\text { East Tiaoxi } \\
\text { Basin }\end{array}$} & False positive rate (\%) & 96 & 96 & 95 & 98 & 97 & 97 & 46 & 20 & 8 \\
\hline & False negative rate $(\%)$ & 97 & 96 & 96 & 98 & 96 & 95 & -- & 59 & 20 \\
\hline & Distance error (m) & 1044 & 1618 & 1270 & 1494 & 1529 & 1194 & 52 & 61 & 19 \\
\hline \multirow{3}{*}{ Hanbei Basin } & False positive rate (\%) & 93 & 94 & 92 & 92 & 88 & 93 & 14 & 19 & 3 \\
\hline & False negative rate $(\%)$ & 93 & 94 & 92 & 93 & 91 & 94 & -- & 75 & 5 \\
\hline & Distance error (m) & 2384 & 2340 & 2092 & 1382 & 1179 & 1061 & 25 & 43 & 19 \\
\hline \multirow{3}{*}{ Eden Basin } & False positive rate (\%) & 91 & 82 & 80 & 90 & 83 & 80 & 76 & 28 & 27 \\
\hline & False negative rate $(\%)$ & 92 & 86 & 83 & 92 & 86 & 83 & -- & 66 & 29 \\
\hline & Distance error $(\mathrm{m})$ & 190 & 94 & 82 & 188 & 94 & 82 & 53 & 34 & 20 \\
\hline
\end{tabular}




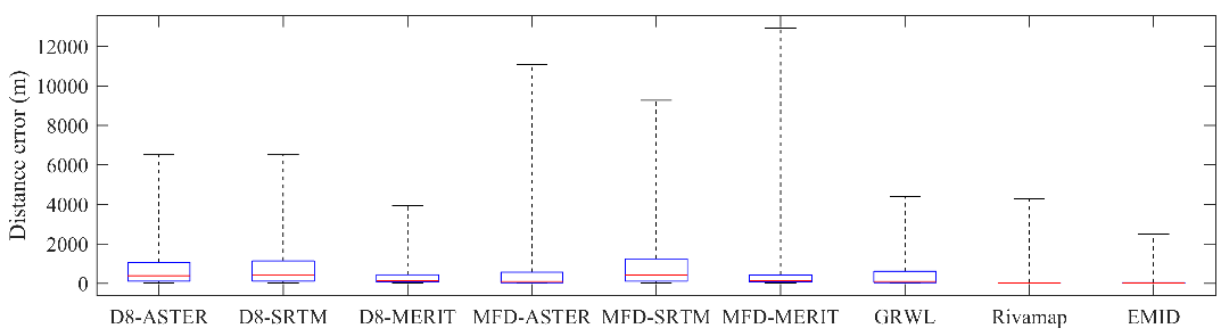

(a) Dongliao River Basin
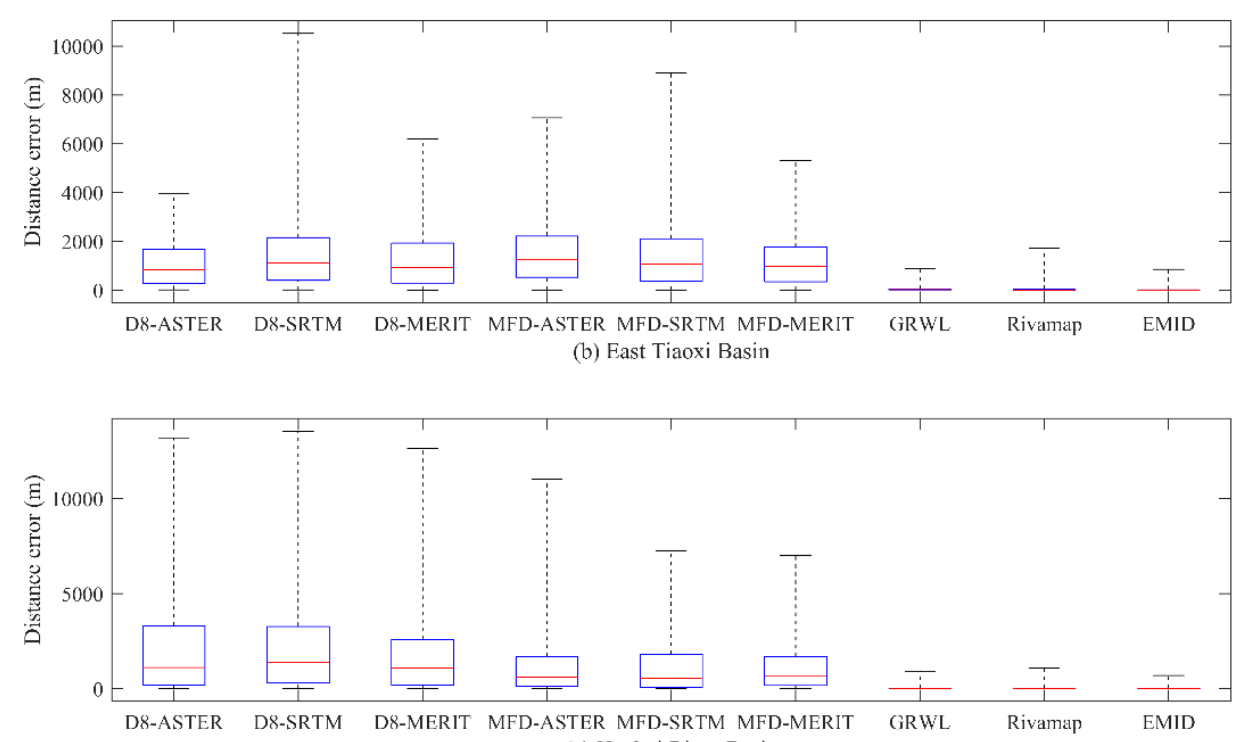

(c) Hanbei River Basin

Fig. 10. Box plots of the distance errors of the river networks extracted using different approaches against the Google Earth references.

\subsubsection{Comparison with Alternative Approaches}

The comparison between the EMID method and alternative approaches is first done visually, with a focus on the locations with representative river features. For the DEM-based methods, the river networks extracted from the open-source DEMs show clear errors and the stream centerlines are erroneously positioned in the Dongliao Basin test case (Fig. S4(a) and Fig. S4(b) of the Supporting Material). For example, the confluence of two rivers extracted by MFDMERIT (as marked by the orange point in Fig. 7(b)), which has both lowest false positive rate and lowest false negative rate among all six set of DEM-based results, deviates from its 'real' location (i.e. the blue point in Fig. 7(b)) for a distance of $6 \mathrm{~km}$. However, the distance error of the same river confluence point extracted by the EMID method is less than $80 \mathrm{~m}$. Unsatisfactory performance of the open-source DEMs also occurs in the Hanbei Basin (Figs. S1(c) and (d)) and the East Tiaoxi Basin (Fig. 8(a)). In Hanbei Basin, the river networks extracted using the 
open-source DEMs do not accurately replicate their layouts and positions, and produce parallel streams, unnaturally straight segments, and angular features, which have also been reported in previous research (e.g. Fairfield \& Leymarie, 1991; Turcotte et al., 2001). In the East Tiaoxi Basin, the DEM-based methods are unable to properly extract the complete rivers connected to Diaocha Lake and the two parallel artificial channels, but they are well captured by the EMID method (Fig. 8(a)).

In comparison with alternative RS-based methods, GRWL and RivaMap do not extract complete river networks, and certain obvious river streams have been left out in the Dongliao Basin (Fig. S4(c) and Fig. S4(d) in the Supporting Material), the East Tiaoxi Basin (Fig. S2(b) in the Supporting Material) and the Hanbei Basin (Fig. 8(a)). For the GRWL products, the omission of rivers is, as expected, mainly due to the fact that it adopts the Landsat scenes captured during the months with near mean discharge and thus the approach can only recognize rivers wider than $30 \mathrm{~m}$ at the mean annual discharge condition (Allen \& Pavelsky, 2018). For Rivamap, it only adopts a single spectral index from mono-temporal imagery and is thus unable to capture some small-scale river streams since a low contrast between water and land surfaces may cause a weak singularity index response (Isikdogan et al., 2017). The use of imagery obtained in wet seasons may potentially extract more complete river networks, but meanwhile may include more 'unreal' rivers (e.g. by treating the temporary water bodies or lakes/reservoirs as 'rivers') than using the imagery in the normal and dry seasons (Fig. S5). Taking the rivers connected to Diaocha lake and two parallel artificial channels in the Hanbei Basin as examples, the RivaMap performs well in extracting rivers connected to Diaocha lake but produces many 'unreal' rivers due to the interference caused by the lake water surface (Fig. 8(b)). Successful extraction of the two artificial channels depends on which RS imagery is adopted (Figs. 8(c), (d) and (e)). The approach clearly fails in the wet season due to temporary inundation covering the area between the two channels (Fig. 8(e)). Besides the mentioned shortcomings, the RivaMap algorithm cannot ensure connectivity of river networks (red box in Fig. 7(c)). Overall, the EMID method out-performs existing DEM-based and RS-based approaches in extracting the layouts and locations of the river networks and ensuring river connectivity.

Table 3 summarizes the quantitative evaluation indices $F P R, F N R$ and ED for different methods or data sources. Given the fact that the GRWL database only includes rivers wider 
than $30 \mathrm{~m}$ and has limited coverage, FNR (i.e. omission error) is not considered for GRWL. The FPRs (i.e. commission errors) calculated for the DEM-based methods (D8-ASTER, D8SRTM, D8-MERIT, MFD-ASTER, MFD-SRTM, and MFD-MERIT) are found to range between $76 \%$ and $98 \%$, with majority of them greater than $90 \%$, which effectively indicates that most of the identified stream pixels are wrongly labeled. Besides, their returned $F N R \mathrm{~s}$ are also the highest among the different approaches applied across all four test basins, ranging between $80 \%$ and $98 \%$, which indicates that most of the stream pixels are wrongly omitted. The distance errors $(E D)$ of river networks directly extracted from DEMs are large (mostly greater than $500 \mathrm{~m}$ ) (Fig. 10), which is consistent with the conclusions from the previous research (e.g. Kumar et al., 2017). The result from the quantitative evaluation clearly demonstrates that the currently available open-source global DEMs are not adequate to support the existing DEM-based methods for river extraction in plain areas.

The RS-based methods are found to produce better results than the D8 and MFD methods across all four test basins. The GRWL river networks produce moderate $F P R$ error $(14 \%-76 \%)$, indicating that less distorted or false rivers are returned by the method. Also, GRWL performs better in detecting the position of stream pixels (with $E D$ ranging between $25 \mathrm{~m}$ and $184 \mathrm{~m}$ ) than the DEM-based methods (Table 3 and Fig. 10) and produces spatially more accurate channels in the flat terrain landscapes. RivaMap returns relatively small FPR errors $(19 \%$ $28 \%)$ but high $F N R$ errors $(59 \%$ - 75\%). The positioning errors $(E D)$ of the RivaMap products are calculated to be within $61 \mathrm{~m}$.

EMID out-performs all of the alternative methods adopted in this work for comparison and derives river networks that are in better agreement with the 'real' rivers. EMID improves $E D$ by almost one order of magnitude in comparison with the DEM-based methods (D8 and MFD method) and by a half against other RS-based methods (GRWL and RivaMap method). As a whole, the evaluation results confirm that EMID produces more favorable results in terms of stream location and coverage across all four study basins, effectively demonstrating it as a better approach for extracting precise river networks when high-resolution DEMs are not available.

\subsubsection{Limitations of the Proposed EMID Method}


Despite its satisfactory performance, EMID also comes with some potential limitations that need attention (Fig. 11). Specifically, as shown in Fig. 11(a), if two rivers are too close to each other and the water surface feature in one of rivers is not obvious, incorrect connection between the river segments may likely occur because the cost of a path through the obvious river feature is less than that through the 'real' river path. In addition, positioning errors or deviation of a river path may occur if certain narrow segments of a river stream cannot be captured by the adopted RS imagery as shown in Fig. 11(b). Whether these river segments can be identified or not depends on their widths at the time when the imagery is acquired and also the spatial resolution of adopted RS imagery. Consequently, the capacity of EMID in extracting small rivers is decided by the spatial resolution, temporal resolution and period length of the adopted RS imagery. For example, when the sentinel-2 imagery is used, it is difficult to identify river segments with a bankful width of less than $10 \mathrm{~m}$ due to the dataset's coverage of a limited period.

Given the fact that only one best path is searched to represent a river stream, the proposed method will not be able to completely extract a river with multiple courses, e.g. an anabranching river. To delineate anabranching rivers more completely, more goal points may be inserted along the channels to find the paths from the starting point to these extra goal points. However, the approach may still return some false negative centerlines (i.e., missing river segments), as shown in Fig. 11(c). Furthermore, when the curvature of a river section is too large and it is not clearly captured on the RS imagery, the searched path is likely to become straightened to cut through the originally curved channel, as shown in Fig. 11(d).

Overall, these limitations impose certain localized effects on the results but do not affect the overall outcomes in terms of layout and position of the extracted river networks. It should be noted that these limitations are difficult to be resolved by only using the water surface map. Future work may be considered to integrate the proposed method with suitable terrain analysis methods to overcome these limitations and achieve higher accuracy in river network delineation. 

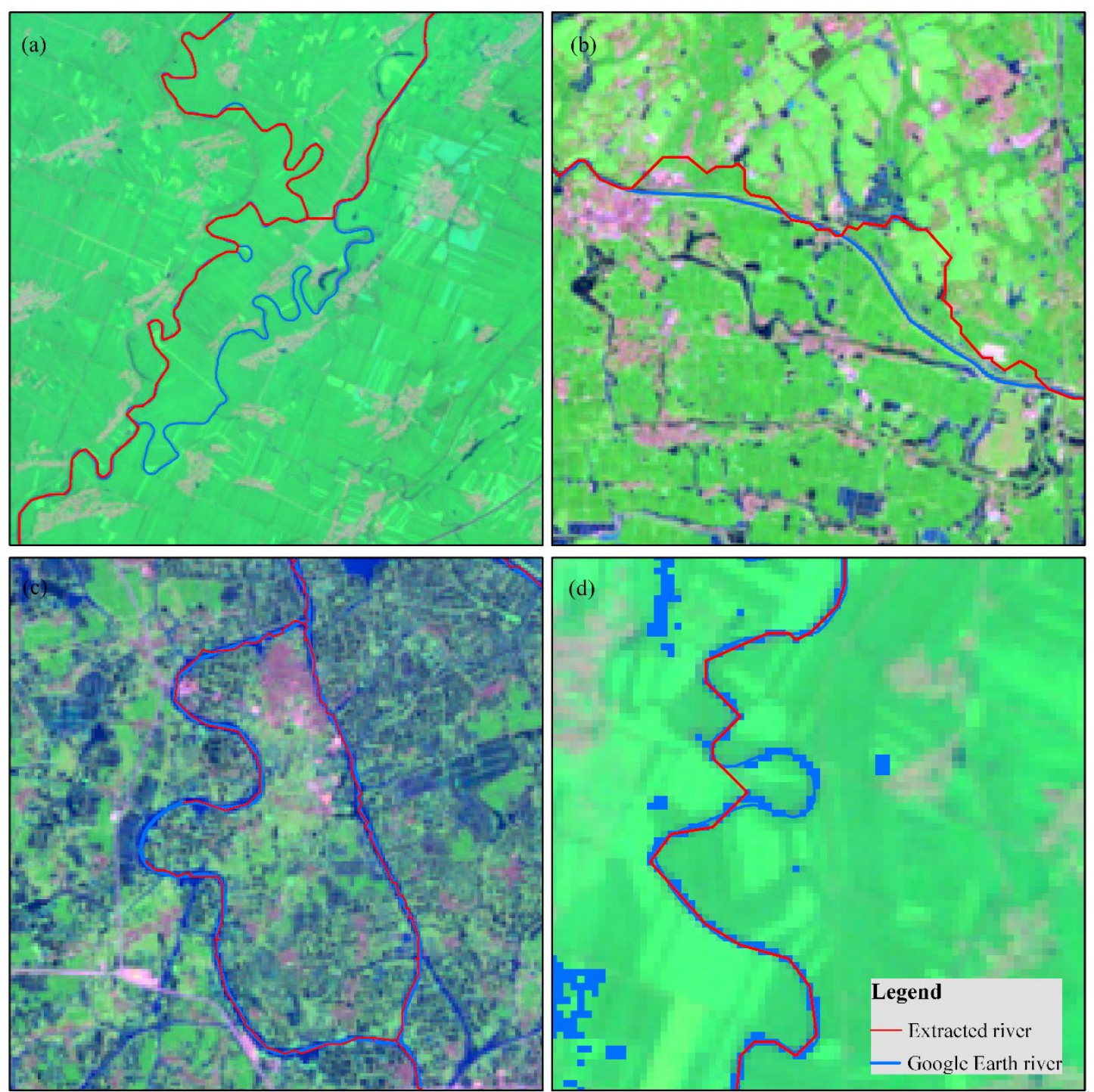

Fig. 11. Certain limitations of the proposed EMID method in extracting river networks.

The background is Landsat 5 TM imagery (bands 7, 4, 2 as red, green, and blue band input in

RGB color space, respectively).

\subsection{Discussion}

717 There exists many non-perennial rivers and streams in addition to perennial rivers, such as snow-melt streams, rain-fed headwater streams, and spring-fed karstic rivers, which account for more than $50 \%$ of the total length of the global river networks (Datry et al., 2014). These non-perennial rivers provide habitat for many species of flora and fauna and are biogeochemical hotspots that retain and transform carbon, nutrients and particulate matters (Skoulikidis et al., 2017). Despite their importance, the data scarcity issue for non-perennial rivers and streams is 
widely acknowledged (e.g. Datry et al., 2014; González-Ferreras \& Barquín, 2017). Given that the signal of non-perennial streams can be effectively detected by the RS imagery acquired at the times when these streams occur (Mohammadi et al., 2017; Chen et al., 2018), the EMID developed in this work uses water surfaces from multi-temporal imagery as inputs to provide a feasible approach for extracting non-perennial rivers.

During the procedure of searching for the best river paths, a power function with a power "a" $>1$ is adopted to convert the water-occurrence frequency to the cost score value. The aim of raising each of cost scores by a power $(>1)$ is to significantly lower the difficulty of a river path to traverse pixels with a high water-occurrence frequency, and to also prevent it from going through pixels with a low water-occurrence frequency. Obviously, it may increase the contrast of cost scores in locations with different water-occurrence frequency. If the power is taken to be 2 , the cost score in a point with $90 \%$ water-occurrence frequency is 100 while that in the point with $10 \%$ frequency is 8100 . It means that the cost of a river passing through a pixel with $10 \%$ frequency is 81 times higher than the one with $90 \%$ frequency. So, this will effectively avoid the river path passing through those pixels with a low likelihood of open water occurrence (such as temporarily inundated floodplains, wetlands, and paddy fields). In this work, the power value of ' 2 ' is recommended and the results in all four test basins do not show obvious difference for higher power values (such as 3 and 4).

The Landsat imagery and Sentinel-2 imagery are used in this study as the inputs to generate water features. However, Landsat imagery with moderate spatial resolution may show a low contrast of the surrounding lands to the river segments with a width $<30 \mathrm{~m}$, and Sentinel-2 imagery with a relatively short-term dataset (4 years) may impede the capture of full information on river streams in different hydrological conditions. Therefore, the small-scale river segments especially those undergoing dynamic changes are difficult to be detected, which may subsequently lead to positioning errors in finding certain river paths (Fig. 10(a), (b) and (d)). Satellite imagery of higher spatial resolution may be used as supplementary data to provide necessary additional information on small-scale river features. For example, sensors (IKONOS, Quickbird, SPOT 5, Orbview) can reach 1-5 m resolution and exhibit higher level of details, which may have a great potential to enrich the information in the Landsat and Sentinel-2 data. The combined data would provide more complete and accurate inputs to support the EMID 
method than a single data source.

Currently, water-occurrence frequency maps are created using a Random Forest model and training data are needed to derive the generic statistical classification rules, which are manually selected via visual interpretation of the RS imagery. Using manually selected training data to create water surface dynamics maps has been reported at catchment scale (e.g., SchafferSmith et al., 2017) and subcontinental scale (e.g., Mueller et al., 2016; Tulbure et al., 2016). Manual selection of training data should not be a big issue when the EMID method is applied in domains of the local or regional scale. But it may limit the application of the approach for water surface classification at the global scale due to the time-consuming manual selection procedure. Automatic classification methods should be further investigated and adopted to process water surface datasets at large-scale domains (Pekel et al. 2016; Zou et al. 2018).

Finally, several global hydrological products have recently been released based on remote sensing imagery and/or DEMs (Frasson et al. 2019; Lin et al. 2019, 2020). The proposed method in this study may be used to improve stream connectivity of these products and help develop a new global hydrological product with improved hydrological connectivity.

\section{CONCLUSIONS}

A new two-stage method, EMID, is proposed in this work to overcome the shortcomings (e.g. broken points, incomplete networks, and the interference of temporary water surface) of the existing RS-based methods for river network delineation. Aiming to extract connected and complete river networks with improved accuracy, EMID utilizes multi-temporal RS imagery and a Random Forest model to synoptically map the location and extent of water surfaces under different hydrological conditions and subsequently provide an optimization algorithm to find the best river paths according to the water-occurrence frequency.

Four test drainage basins with flat terrains but different hydrological and river morphological features are used to validate the proposed method by comparing the river extraction results with the reference river networks mapped from surveyed data or more reliable source and produced using different DEM-based and RS-based methods. The proposed EMID method is demonstrated to consistently out-perform the alternative methods by returning lowest false positive rate, lowest false negative rate and minimum distance error. This confirms that, 
compared with the DEM-based methods, EMID provides an approach to extract river networks with improved accuracy when high-resolution DEMs are not available. Also, in comparison with other existing RS-based methods, the river networks extracted by EMID are more complete and better resolved with higher stream connectivity.

The EMID method and Sentinel archives can potentially be used to develop a new global river product that includes all of the $10 \mathrm{~m}$ and wider rivers. This product would offer more precise river network information for relevant research, such as flood modeling, water resource management and biogeochemical cycles characterizing, etc. Furthermore, the EMID method and Landsat archives are able to produce global river datasets documenting river stream changes over the past several decades, which can help scientists better understand the impact of climate change and human activity on hydrological changes over space and time. In the future, we also plan to explore the integration of the EMID method and terrain analysis to achieve even higher accuracy in river network delineation.

\section{ACKNOWLEDGMENTS}

This work is supported by the WeACT project (NE/S005919/1) funded by the UK Natural Environment Research Council (NERC), National Science Foundation of China (51721006), the River Basins as 'Living Laboratories' project (NE/S012427/1) funded by the UK Natural Environment Research Council (NERC) and High-performance Computing Platform of Peking University. MATLAB codes for extracting rivers from the water-occurrence frequency map and the data including river networks of three drainage basins and the training data for these basins can be found in https://github.com/Huilichen1989/EMID_RiverExtraction.

\section{REFERENCES}

Allen, G. H., \& Pavelsky, T. M. (2018). Global extent of rivers and streams. Science, 361(6402), $585-588$.

Bai, R., Li, T., Huang, Y., Li, J., \& Wang, G. (2015a). An efficient and comprehensive method for drainage network extraction from DEM with billions of pixels using a size-balanced binary search tree. Geomorphology, 238, 56-67.

Bai, R., Tiejian, L., Huang, Y., Jiaye, L., Wang, G., \& Yin, D. (2015b). A hierarchical pyramid method for managing large-scale high-resolution drainage networks extracted from DEM. Computers \& geosciences, 85, 234-247. 
Battin, T. J., Kaplan, L. A., Findlay, S., Hopkinson, C. S., Marti, E., \& Packman, A. I., et al. (2009). Biophysical controls on organic carbon fluxes in fluvial networks. Nature Geoscience, 1(8), 95-100.

Benstead, J. P., \& Leigh, D. S. (2012). An expanded role for river networks. Nature Geoscience, 5(10), 678-679.

Bird, S., Dan, H., \& Schwab, J. (2010). Photogrammetric monitoring of small streams under a riparian forest canopy. Earth Surface Processes \& Landforms, 35(8), 952-970.

Boix-Fayos, C., Barberá, G. G., López-Bermúdez, F., \& Castillo, V. M. (2007). Effects of check dams, reforestation and land-use changes on river channel morphology: case study of the Rogativa catchment (Murcia, Spain). Geomorphology, 91(1), 103-123.

Breiman, L. (2001). Random forests. Machine learning, 45(1), 5-32.

Cazorzi, F., Fontana, G. D., Luca, A. D., Sofia, G., \& Tarolli, P. (2013). Drainage network detection and assessment of network storage capacity in agrarian landscape. Hydrological Processes, 27(4), 541-553.

Chander, G., Markham, B. L., \& Helder, D. L. (2009). Summary of current radiometric calibration coefficients for Landsat MSS, TM, ETM+, and EO-1 ALI sensors. Remote Sensing of Environment, 113, 893-903.

Chen, H., Liang, Q., Liu, Y., \& Xie, S. (2018). Hydraulic correction method (HCM) to enhance the efficiency of SRTM DEM in flood modeling. Journal of Hydrology, 559, 56-70

Church, M. (2002). Geomorphic thresholds in riverine landscapes. Freshwater biology, 47(4), 541-557.

Cole, J. J., Y. T. Prairie, N. F. Caraco, W. H. McDowell, L. J. Tranvik, R. G. Striegl, C. M. Duarte, P. Kortelainen, J. A. Downing, J. J. Middelburg \& J. Melack. (2007). Plumbing the global carbon cycle: integrating inland waters into the terrestrial carbon budget. Ecosystems, $10(1), 172-185$.

Dai, Y., Ikeshima, D., Tawatari, R., Yamaguchi, T., O'Loughlin, F., \& Neal, J. C., et al. (2017). A high-accuracy map of global terrain elevations. Geophysical Research Letters, 44(11), 5844-5853.

Datry, T., Larned, S. T., \& Tockner, K. (2014). Intermittent rivers: a challenge for freshwater ecology. BioScience, 64(3), 229-235.

Deng, Z., Zhang, X., Li, D., \& Pan, G. (2015). Simulation of land use/land cover change and its effects on the hydrological characteristics of the upper reaches of the Hanjiang Basin. Environmental Earth Sciences, 73(3), 1119-1132.

Dillabaugh, C. R., Niemann, K. O., \& Richardson, D. E. (2002). Semi-automated extraction of rivers from digital imagery. GeoInformatica, 6(3), 263-284.

Dong, J., Xiao, X., Kou, W., Qin, Y., Zhang, G., \& Li, L., et al. (2015). Tracking the dynamics of paddy rice planting area in 1986-2010 through time series Landsat images and phenology-based algorithms. Remote Sensing of Environment, 160(160), 99-113.

Dottori, F., Szewczyk, W., Ciscar, J. C., Zhao, F., Alfieri, L., \& Hirabayashi, Y., et al. (2018). Increased human and economic losses from river flooding with anthropogenic warming. Nature Climate Change. 8(9), 781.

Fairfield, J., \& Leymarie, P. (1991). Drainage networks from grid digital elevation models. Water Resources Research, 27(5), 709-717.

Farr, T. G., Rosen, P. A., Caro, E., Crippen, R., Duren, R., \& Hensley, S., et al. (2007). The 
shuttle radar topography mission. Reviews of Geophysics, 45(2), 361.

Feng, L., Hu, C., Chen, X., Cai, X., Tian, L., \& Gan, W. (2012). Assessment of inundation changes of Poyang Lake using MODIS observations between 2000 and 2010. Remote Sensing of Environment, 121, 80-92.

Feng, L., Hu, C., Chen, X., \& Zhao, X. (2013). Dramatic inundation changes of China's two largest freshwater lakes linked to the Three Gorges Dam. Environmental science \& technology, 47(17), 9628-9634.

Feyisa, G. L., Meilby, H., Fensholt, R., \& Proud, S. R. (2014). Automated Water Extraction Index: A new technique for surface water mapping using Landsat imagery. Remote Sensing of Environment, 140(1), 23-35.

Frasson, R.P.D.M., Pavelsky, T.M., Fonstad, M.A., Durand, M.T., Allen, G.H., Schumann, G., Lion, C., Beighley, R.E. \& Yang, X. (2019). Global relationships between river width, slope, catchment area, meander wavelength, sinuosity, and discharge. Geophysical Research Letters, 46(6), 3252-3262.

Frazier, P. S., \& Page, K. J. (2000). Water body detection and delineation with Landsat TM data. Photogrammetric engineering and remote sensing, 66(12), 1461-1468.

Fujisada, H., Urai, M., \& Iwasaki, A. (2012). Technical methodology for ASTER global DEM. IEEE Transactions on Geoscience and Remote Sensing, 50(10), 3725-3736.

Gleason, C. J., \& Smith, L. C. (2014). Toward global mapping of river discharge using satellite images and at-many-stations hydraulic geometry. Proceedings of the National Academy of Sciences of the United States of America, 111(13), 4788.

González-Ferreras, A. M., \& Barquín, J. (2017). Mapping the temporary and perennial character of whole river networks. Water Resources Research, 53(8), 6709-6724.

Gurnell, A. (2014). Plants as river system engineers. Earth Surface Processes \& Landforms, $39(1), 4-25$.

Handcock, R. N., Gillespie, A. R., Cherkauer, K. A., Kay, J. E., Burges, S. J., \& Kampf, S. K. (2006). Accuracy and uncertainty of thermal-infrared remote sensing of stream temperatures at multiple spatial scales. Remote Sensing of Environment, 99(4), 427-440.

Hawker, L., Bates, P., Neal, J., \& Rougier, J. (2018). Perspectives on Digital Elevation Model (DEM) Simulation for Flood Modeling in the Absence of a High-Accuracy Open Access Global DEM. Frontiers in Earth Science, 6, 233, 1-9.

Holmgren, P. (1994). Multiple flow direction algorithms for runoff modelling in grid based elevation models: an empirical evaluation. Hydrological processes, 8(4), 327-334.

Hudak, A. T., Crookston, N. L., Evans, J. S., Hall, D. E., \& Falkowski, M. J. (2008). Nearest neighbor imputation of species-level, plot-scale forest structure attributes from LiDAR data. Remote Sensing of Environment, 112(5), 2232-2245.

Huete, A., Didan, K., Miura, T., Rodriguez, E. P., Gao, X., \& Ferreira, L. G. (2002). Overview of the radiometric and biophysical performance of the MODIS vegetation indices. Remote sensing of environment, 83(1-2), 195-213.

Isikdogan, F., Bovik, A., \& Passalacqua, P. (2015). Automatic channel network extraction from remotely sensed images by singularity analysis. IEEE Geoscience \& Remote Sensing Letters, 12(11), 2218-2221.

Isikdogan, F., Bovik, A., \& Passalacqua, P. (2017). RivaMap: An automated river analysis and mapping engine. Remote Sensing of Environment, 202, 88-97. 
Jasiewicz, J., \& Metz, M. (2011). A new GRASS GIS toolkit for Hortonian analysis of drainage networks. Computers \& Geosciences, 37(8), 1162-1173.

Jiang, H., Feng, M., Zhu, Y., Lu, N., Huang, J., \& Xiao, T. (2014). An automated method for extracting rivers and lakes from Landsat imagery. Remote Sensing, 6(6), 5067-5089.

Jin, Z., Zheng, Q., Zhu, C., Wang, Y., Cen, J., \& Li, F. (2018). Contribution of nitrate sources in surface water in multiple land use areas by combining isotopes and a Bayesian isotope mixing model. Applied Geochemistry, 93, 10-19.

Jones, K. L., Poole, G. C., O'Daniel, S. J., Mertes, L. A. K., \& Stanford, J. A. (2008). Surface hydrology of low-relief landscapes: assessing surface water flow impedance using LIDARderived digital elevation models. Remote Sensing of Environment, 112(11), 4148-4158.

Koenders, R., Lindenbergh, R. C., Storms, J. E., \& Menenti, M. (2014). Multiscale curvatures for identifying channel locations from DEMs. Computers \& Geosciences, 68, 11-21.

Kumar, B., Patra, K. C., \& Lakshmi, V. (2017). Error in digital network and basin area delineation using d8 method: A case study in a sub-basin of the Ganga. Journal of the Geological Society of India, 89(1), 65-70.

Li, J., Huang, L., Sato, T., Zou, L., Jiang, K., \& Yahara, T., et al. (2013). Distribution pattern, threats and conservation of fish biodiversity in the East Tiaoxi, China. Environmental Biology of Fishes, 96(4), 519-533.

Lin, P., Pan, M., Beck, H.E., Yang, Y., Yamazaki, D., Frasson, R., David, C.H., Durand, M., Pavelsky, T.M., Allen, G.H. \& Gleason, C. J. (2019). Global reconstruction of naturalized river flows at 2.94 million reaches. Water resources research, 55(8), 6499-6516.

Lin, P., Pan, M., Allen, G. H., de Frasson, R. P., Zeng, Z., Yamazaki, D., \& Wood, E. F. (2020). Global Estimates of Reach - Level Bankfull River Width Leveraging Big Data Geospatial Analysis. Geophysical Research Letters, 47(7).

Loveland, T. R., \& Dwyer, J. L. (2012). Landsat: Building a strong future. Remote Sensing of Environment, 122, 22-29.

Malinowski, R., Höfle, B., Koenig, K., Groom, G., Schwanghart, W., \& Heckrath, G. (2016). Local-scale flood mapping on vegetated floodplains from radiometrically calibrated airborne LiDAR data. ISPRS Journal of Photogrammetry and Remote Sensing, 119, 267279.

Marchese, E., Scorpio, V., Fuller, I., McColl, S., \& Comiti, F. (2017). Morphological changes in Alpine rivers following the end of the Little Ice Age. Geomorphology, 295, 811-826.

Martz, L. W., \& Garbrecht, J. (1992). Numerical definition of drainage network and subcatchment areas from digital elevation models. Computers \& Geosciences, 18(6), 747761.

McFeeters, S. K. (1996). The use of the Normalized Difference Water Index (NDWI) in the delineation of open water features. International journal of remote sensing, 17(7), 14251432.

Mohammadi, A., Costelloe, J. F., \& Ryu, D. (2017). Application of time series of remotely sensed normalized difference water, vegetation and moisture indices in characterizing flood dynamics of large-scale arid zone floodplains. Remote sensing of environment, 190, 70-82.

Mohammed, N. Z., Ghazi, A., \& Mustafa, H. E. (2013). Positional accuracy testing of Google Earth. International Journal of Multidisciplinary Sciences and Engineering, 4(6), 6-9.

Moore, I. D., Grayson, R. B., \& Ladson, A. R. (1991). Digital terrain modelling: a review of hydrological, geomorphological, and biological applications. Hydrological Processes, 5(1), 
Moretti, G., \& Orlandini, S. (2008). Automatic delineation of drainage basins from contour elevation data using skeleton construction techniques. Water resources research, 44(5), W05403.

Moretti, G., \& Orlandini, S. (2018). Hydrography - Driven Coarsening of Grid Digital Elevation Models. Water Resources Research, 54(5), 3654-3672.

Mueller, N., Lewis, A., Roberts, D., Ring, S., Melrose, R., Sixsmith, J., Lymburner, L., McIntyre, A., Tan, P., Curnow, S. and Ip, A. (2016). Water observations from space: Mapping surface water from 25 years of Landsat imagery across Australia. Remote Sensing of Environment, 174, 341-352.

O'Callaghan, J. F., \& Mark, D. M. (1984). The extraction of drainage networks from digital elevation data. Computer vision, graphics, and image processing, 28(3), 323-344.

Orengo, H. A., \& Petrie, C. A. (2017). Large-scale, multi-temporal remote sensing of palaeoriver networks: a case study from northwest India and its implications for the Indus Civilisation. Remote Sensing, 9(7), 735.

Orlandini, S., \& Moretti, G. (2009). Determination of surface flow paths from gridded elevation data. Water resources research, 45(3), W03417.

Orlandini, S., Moretti, G., \& Gavioli, A. (2014). Analytical basis for determining slope lines in grid digital elevation models. Water Resources Research, 50(1), 526-539.

Orlandini, S., Moretti, G., Corticelli, M. A., Santangelo, P. E., Capra, A., Rivola, R., \& Albertson, J. D. (2012). Evaluation of flow direction methods against field observations of overland flow dispersion. Water Resources Research, 48(10), W10523.

Orlandini, S., Moretti, G., Franchini, M., Aldighieri, B., \& Testa, B. (2003). Path - based methods for the determination of nondispersive drainage directions in grid - based digital elevation models. Water resources research, 39(6), 1144.

Orlandini, S., Tarolli, P., Moretti, G., \& Dalla Fontana, G. (2011). On the prediction of channel heads in a complex alpine terrain using gridded elevation data. Water Resources Research, 47(2), W02538.

Passalacqua, P., Tarolli, P., \& Foufoula-Georgiou, E. (2010a). Testing space-scale methodologies for automatic geomorphic feature extraction from LIDAR in a complex mountainous landscape. Water Resources Research, 46(11), 208-217.

Passalacqua, P., Do Trung, T., Foufoula - Georgiou, E., Sapiro, G., \& Dietrich, W. E. (2010b). A geometric framework for channel network extraction from lidar: Nonlinear diffusion and geodesic paths. Journal of Geophysical Research: Earth Surface, 115, F01002.

Pavelsky, T. M., \& Smith, L. C. (2008). Rivwidth: a software tool for the calculation of river widths from rotely sensed imagery. IEEE Geoscience \& Remote Sensing Letters, 5(1), 7073.

Pekel, J. F., Cottam, A., Gorelick, N., \& Belward, A. S. (2016). High-resolution mapping of global surface water and its long-term changes. Nature, 540(7633), 418-422.

Poppenga, S. K., Worstell, B. B., Stoker, J. M., \& Greenlee, S. K. (2010). Using selective drainage methods to extract continuous surface flow from 1-meter LiDAR-derived digital elevation data. U.S. Geological Survey Scientific Investigations Report.

Pulighe, G., Baiocchi, V., \& Lupia, F. (2016). Horizontal accuracy assessment of very high resolution Google Earth images in the city of Rome, Italy. International Journal of Digital 
Earth, 9(4), 342-362.

Qin, L., Xu, W., Tian, Y., Chen, B., \& Wang, S. (2018). A River Channel Extraction Method for Urban Environments Based on Terrain Transition Lines. Water Resources Research, 54(7), 4887-4900.

Rabus, B., Eineder, M., Roth, A., \& Bamler, R. (2003). The shuttle radar topography missiona new class of digital elevation models acquired by spaceborne radar. ISPRS journal of photogrammetry and remote sensing, 57(4), 241-262.

Rodriguez-Galiano, V. F., Ghimire, B., Rogan, J., Chica-Olmo, M., \& Rigol-Sanchez, J. P. (2012). An assessment of the effectiveness of a random forest classifier for land-cover classification. ISPRS Journal of Photogrammetry and Remote Sensing, 67, 93-104.

Roelens, J., Rosier, I., Dondeyne, S., Van Orshoven, J., \& Diels, J. (2018). Extracting drainage networks and their connectivity using LiDAR data. Hydrological Processes, 32(8), 10261037.

Rosemond, A. D., Benstead, J. P., Bumpers, P. M., Gulis, V., Kominoski, J. S., \& Manning, D. W., et al. (2015). Freshwater ecology. Experimental nutrient additions accelerate terrestrial carbon loss from stream ecosystems. Science, 347(6226), 1142-5.

Schaffer-Smith, D., Swenson, J. J., Barbaree, B., \& Reiter, M. E. (2017). Three decades of Landsat-derived spring surface water dynamics in an agricultural wetland mosaic; Implications for migratory shorebirds. Remote sensing of environment, 193, 180-192.

Schneider, A., Jost, A., Coulon, C., Silvestre, M., Théry, S., \& Ducharne, A. (2017). Global scale river network extraction based on high - resolution topography and constrained by lithology, climate, slope, and observed drainage density. Geophysical Research Letters, 44(6), 2773-2781.

Schumann, G. J. P., \& Bates, P. D. (2018). The Need for a High-Accuracy, Open-Access Global DEM. Frontiers in Earth Science, 6, 225.

Seibert, J., \& McGlynn, B. L. (2007). A new triangular multiple flow direction algorithm for computing upslope areas from gridded digital elevation models. Water resources research, 43(4), W04501.

Shen, D., \& Sheng, Y. (2012). Area partitioning for channel network extraction using digital elevation models and remote sensing. IEEE Geoscience and Remote Sensing Letters, 9(2), 194-198.

Skoulikidis, N. T., Sabater, S., Datry, T., Morais, M. M., Buffagni, A., \& Dörflinger, Gerald, et al. (2017). Non-perennial Mediterranean rivers in Europe: status, pressures, and challenges for research and management. Science of the Total Environment, 577, 1-18.

Sofia, G., Tarolli, P., Cazorzi, F., \& Dalla Fontana, G. (2011). An objective approach for feature extraction: distribution analysis and statistical descriptors for scale choice and channel network identification. Hydrology and earth system sciences, 15(5), 1387-1402.

Su, S., Wang, Y., Luo, F., Mai, G., \& Pu, J. (2014). Peri-urban vegetated landscape pattern changes in relation to socioeconomic development. Ecological indicators, 46, 477-486.

Svoray, T. (2004). Integrating automatically processed SPOT HRV Pan imagery in a DEMbased procedure for channel network extraction. International Journal of Remote Sensing, 25(17), 3541-3547.

Tucker, C. J. (1979). Red and photographic infrared linear combinations for monitoring vegetation. Remote sensing of Environment, 8(2), 127-150.

Tulbure, M. G., Broich, M., Stehman, S. V., \& Kommareddy, A. (2016). Surface water extent 
dynamics from three decades of seasonally continuous Landsat time series at subcontinental scale in a semi-arid region. Remote Sensing of Environment, 178, 142-157.

Turcotte, R., Fortin, J. P., Rousseau, A. N., Massicotte, S., \& Villeneuve, J. P. (2001). Determination of the drainage structure of a watershed using a digital elevation model and a digital river and lake network. Journal of hydrology, 240(3-4), 225-242.

Van De Wiel, M. J., Coulthard, T. J., Macklin, M. G., \& Lewin, J. (2011). Modelling the response of river systems to environmental change: progress, problems and prospects for palaeo-environmental reconstructions. Earth-Science Reviews, 104(1-3), 167-185.

Veh, G., Korup, O., Roessner, S., \& Walz, A. (2018). Detecting Himalayan glacial lake outburst floods from Landsat time series. Remote Sensing of Environment, 207, 84-97.

Verpoorter, C., Kutser, T., \& Tranvik, L. (2012). Automated mapping of water bodies using Landsat multispectral data. Limnology and Oceanography: Methods, 10(12), 1037-1050.

Ward, P. J., Jongman, B., Aerts, J. C. J. H., Bates, P. D., Botzen, W. J. W., \& Loaiza, A. D., et al. (2017). A global framework for future costs and benefits of river-flood protection in urban areas. Nature Climate Change, 7(9), 642.

$\mathrm{Xu}$, H. (2006). Modification of normalised difference water index (NDWI) to enhance open water features in remotely sensed imagery. International journal of remote sensing, 27(14), 3025-3033.

Yamazaki, D., Ikeshima, D., Sosa, J., Bates, P. D., Allen, G., \& Pavelsky, T. (2019). MERIT Hydro: A high-resolution global hydrography map based on latest topography datasets. Water Resources Research, 55, 5053-5073

Yamazaki, D., O'Loughlin, F., Trigg, M. A., Miller, Z. F., Pavelsky, T. M., \& Bates, P. D. (2014). Development of the global width database for large rivers. Water Resources Research, 50(4), 3467-3480.

Yamazaki, D., Trigg, M. A., \& Ikeshima, D. (2015). Development of a global $90 \mathrm{~m}$ water body map using multi-temporal Landsat images. Remote Sensing of Environment, 171, 337-351.

Yang, K., Li, M., Liu, Y., Cheng, L., Duan, Y., \& Zhou, M. (2014). River delineation from remotely sensed imagery using a multi-scale classification approach. IEEE Journal of Selected Topics in Applied Earth Observations and Remote Sensing, 7(12), 4726-4737.

Yang, K., Li, M., Liu, Y., Cheng, L., Huang, Q., \& Chen, Y. (2015). River detection in remotely sensed imagery using Gabor filtering and path opening. Remote Sensing, 7(7), 8779-8802.

Yang, X., Lin, E., Ma, S., Ju, H., Guo, L., \& Xiong, W., et al. (2007). Adaptation of agriculture to warming in northeast china. Climatic Change, 84(1), 45-58.

Yu, X., Hyyppä, J., Vastaranta, M., Holopainen, M., \& Viitala, R. (2011). Predicting individual tree attributes from airborne laser point clouds based on the random forests technique. ISPRS Journal of Photogrammetry and Remote Sensing, 66(1), 28-37.

Zeng, C., Bird, S., Luce, J. J., \& Wang, J. (2015). A natural-rule-based-connection (NRBC) method for river network extraction from high-resolution imagery. Remote Sensing, 7(10), 14055-14078.

Zhang, L., Lu, W., Yang, Q., An, Y., Li, D., \& Gong, L. (2012). Hydrological impacts of climate change on streamflow of Dongliao River watershed in Jilin Province, China. Chinese geographical science, 22(5), 522-530.

Zhou, M., \& Peng, X. (2011). Study on the countermeasures of water ecology and water environment protection in Hanbei River. Proceedings of the thematic forum on the water ecology and water environment of River and Lake. 
1079 Zou, Z., Xiao, X., Dong, J., Qin, Y., Doughty, R. B., \& Menarguez, M. A., et al. (2018).

1080 Divergent trends of open-surface water body area in the contiguous United States from 1984 to 2016. Proceedings of the National Academy of Sciences, 115(15), 3810-3815. 


\section{List of Figure Captions}

1083 Fig. 1. The EMID framework that combines multi-temporal imagery and a path tracking technique 1084 for river network extraction.

1085 Fig. 2. A simple example of finding the best river path using the proposed optimization algorithm.

1086 Fig. 3. The four test basins and the river networks.

1087 Fig. 4. Extracted water surface areas in the Dongliao Basin.

1088 Fig. 5. Water-occurrence frequency maps in the East Tiaoxi Basin.

1089 Fig. 6. Water-occurrence frequency maps in the Hanbei Basin.

1090 Fig. 7. Comparison between the river networks derived from different methods and the reference 1091 river network manually mapped from Google Earth in the Dongliao Basin.

1092 Fig. 8. Comparison between the river networks derived from different methods and the Google Earth. 1093 Fig. 9. Comparison between the river networks derived from the Sentinel imagery using the 1094 proposed EMID method and the field surveyed data for the Eden Catchment.

1095 Fig. 10. Box plots of the distance errors of the river networks extracted using different approaches 1096 against the Google Earth references.

1097 Fig. 11. Certain limitations of the proposed EMID method in extracting river networks. 